\title{
FINANCIAL DISTRESS PREDICTION: A NOVEL DATA SEGMENTATION RESEARCH ON CHINESE LISTED COMPANIES
}

\author{
Fang-Jun ZHU (D) 1,2,3, Lu-Juan ZHOU (D) 1,2,3*, \\ Mi ZHOU (D) 1,2,3\#, Feng PEI (D) 1,2,3 \\ ${ }^{1}$ School of Management, Hefei University of Technology, Hefei, 230009 Anhui, China \\ ${ }^{2}$ Engineering Research Center for Intelligent Decision-Making and Information System Technologies, \\ Ministry of Education, Hefei, 230009 Anhui, China \\ ${ }^{3}$ Key Laboratory of Process Optimization and Intelligent Decision-Making, \\ Ministry of Education, Hefei, 230009 Anhui, China
}

Received 29 December 2020; accepted 28 June 2021; first published online 04 November 2021

\begin{abstract}
In the Chinese stock market, the unique special treatment (ST) warning mechanism can signal financial distress for listed companies. In existing studies, classification model has been developed to differentiate the two general listing states. However, this classification model cannot explain the internal changes of each listing state. Considering that the requirement of the withdrawal of ST in the mechanism is relatively loose, we propose a new segmentation approach for Chinese listed companies, which are divided into negative companies and positive companies according to the number of times being labeled ST. Under the framework of data mining, we use financial indicators, non-financial indicators, and time series to build a financial distress prediction model of distinguishing the long-term development of different Chinese listed companies. Through data segmentation, we find that the negative samples have a huge destructive interference on the prediction effect of the total sample. On the contrary, positive companies improve the prediction accuracy in all aspects and the optimal feature set is also different from all companies. The main contribution of the paper is to analyze the internal impact of the deterioration of financial distress prediction in time series and construct an optimization model for positive companies.
\end{abstract}

Keywords: financial distress prediction, Chinese listed companies, ensemble learning, data mining, data segmentation, special treatment.

JEL Classification: G01, G17, G32.

\section{Introduction}

Financial distress prediction is an emerging research topic. A troubled company will have a huge impact on the entire financial system of business owners, investors, and credit institutions. How to distinguish a troubled company from normal companies is undoubtedly

*Corresponding author. E-mail: zhoulujuan1002@163.com

\#Corresponding author. E-mail: zhoumi83@163.com

Copyright (c) 2021 The Author(s). Published by Vilnius Gediminas Technical University

This is an Open Access article distributed under the terms of the Creative Commons Attribution License (http://creativecommons. org/licenses/by/4.0/), which permits unrestricted use, distribution, and reproduction in any medium, provided the original author and source are credited. 
very important. As China becomes one of the main markets for international investors, the financial distress prediction of Chinese companies has attracted more and more attention.

The unique ST warning mechanism is implemented by the CSRC to indicate the abnormal status of listed companies, including abnormal financial status and other abnormal status. A company will receive ST warnings, when the company has suffered losses for two consecutive years. On the contrary, if the financial status or other status of a ST labeled company has been improved, the CSRC will withdraw the ST warning. Therefore, the purpose of ST is to release the signal of warning to managers and investors.

However, there are many inferior companies in the Chinese market that have been warned many times and have chaotic operations. These companies can still get opportunities in the market. For example, Shenzhen Kondarl's performance dropped by $200 \%$, but its stock price soared in 2010. And China Diving's performance dropped by 25\%, but the stock price still soared nearly four times in 2019. These companies will mess up the stock market, and the prediction effect of these companies' prediction problems is very bad (Zhou, 2013). In other words, the "ST label can be withdrawn" mechanism will provide convenience to companies with chaotic financial conditions, whose financial conditions are usually unpredictable. Inferior companies can repeatedly get rid of ST labels within a period of time. Among the ST companies surveyed in this article in the past three years, $45 \%$ have a history of multiple warnings. Many researches are based on Chinese companies as the research background (Mousavi \& Lin, 2020; Wang et al., 2020; Sun et al., 2020), and take listing state as the target variable, but most of them focus on feature expansion and model optimization. However, it has not considered that this mechanism itself will have an impact on financial distress forecasts.

Therefore, it is necessary to further subdivide listed companies to explore the optimization space and mutual relationship of different types of companies. This paper uses a data segmentation approach, the analysis framework of data mining (Olson et al., 2012) and some well-performing models (Lin et al., 2012) for financial distress prediction analysis under time series. The contributions of this paper are as follows:

1. A novel data segmentation research based on the number of times being labeled ST is proposed. The listed companies are divided into negative companies and positive companies, which enhances the prediction accuracy for the financial distress of Chinese listed companies.

2. Comparative experiment is conducted on all listed companies, negative companies, and positive companies. The result shows that the negative companies undermine the financial prediction effect of Chinese listed companies due to its intrinsic characteristics.

3. The feature selection method aimed at constructing different indicator systems reveals that the financial distress prediction effect of positive companies is better, which provides a new perspective for the financial distress prediction of Chinese listed companies.

The remainder of this paper is organized as follows. Section 1 presents a literature review related to the field of financial distress. The research framework and part of the experimental analysis are described in Section 2. In Section 3, the analysis based on the results is conducted, followed by the feature extraction mechanism implemented in this paper. This paper is concluded in the last section. 


\section{Literature review}

\subsection{Research background}

Financial distress is a term used in corporate finance to indicate a situation in which the promise to the creditors of the company has been violated or is difficult to fulfill. In most cases, when distinguishing between failed and non-failed companies, the authors often use bankruptcy as the dividing line (Wang et al., 2014). However, in the Chinese stock market, it is difficult to obtain data on bankrupt companies. Therefore, the research on the prediction of financial distress in the Chinese market usually uses the ST label stipulated by CSRC as the dividing line (Zhou et al., 2016). Although ST also includes other anomalies, this article will consider ST's judgment rules based on financial status as other studies.

According to the listing rules, if the financial situation of a company with an ST label has improved to the extent that it meets certain specific requirements, then the ST label can be withdrawn (Zhou, 2013). In other words, a normal company in China may encounter financial distress and be delisted from the stock market, while a company in financial distress may resume its normal company status. The ST label will affect the credit risk assessment of the company by creditors, suppliers, and customers, and ultimately affect the company's stock price and increase the its delisting risk (Zhou et al., 2016). If the financial status of the listed company returns to normal in recent years, i.e., the audit results show that the abnormal financial status has been eliminated, and the company's net profit is positive after deducting non-recurring gains and losses, the company can apply to the exchange to cancel the special treatment. The withdrawal of ST is mainly based on the company's situation in the year of the application period. Comparatively, obtaining the ST label should satisfy the condition that the company's financial status continued losses for two consecutive years. It can be seen that it is easier to withdraw the ST label. In order to avoid delisting, many listed companies run risks to adjust their profits through earnings management. The whitewashed earnings information will mislead investors, especially for small and medium investors, and cause them to make wrong decisions in investment (Farisha et al., 2012). What's more, some companies cycle from being labeled ST to being withdrawn, and then being labeled again, and regard ST rules as a "safe haven", which disrupts the order of transactions in the capital market of China (Zhou et al., 2016). Most studies did not consider the operability of the rules for revocation of ST, but only used the ST label of the current year as the label for classification prediction. If an inferior company is repeatedly received ST warning, it is difficult for us to judge its true financial status by the ST label of the current year. Based on this, we use the special treatment change records to distinguish companies with different levels of behavior, so as to discover the impact of such inferior companies on financial forecasts.

In order to reflect the dynamic impact of inferior companies on financial forecasts, it is meaningless to collect the financial data of listed companies only in the previous 1 or 2 years (Ding et al., 2008). According to ST rules, a company needs to satisfy the condition of two consecutive years of loss to obtain an ST label. Therefore, for any type of ST company, the financial data of the previous 1 or 2 years will show poor financial status and cannot distinguish the behavior of inferior companies. It is meaningful to make earlier financial distress forecasts, and it is easier to discover the influence of inferior companies in the financial 
prediction process. Inspired by Geng et al. (2015), this paper collected the financial data of listed companies in the first 3, 4 and 5 years, and constructed a prediction model for each time period.

This research takes into account the blind-spot of ST rules. By making full use of special treatment change records and extending the time span of historical data, it is conducive to accurately reflect the dynamic impact of inferior companies on financial forecasts. The subsequent optimization is effectively carried out through data segmentation approach.

\subsection{Research method}

In the field of financial distress prediction, data mining techniques are often used (Zhou et al., 2015), and the results are generated in the modeling process (Olson et al., 2012). The CRISP-DM (Shearer, 2000) model occupies a leading position in various knowledge discovery in database (KDD) models. Its data mining process includes business understanding, data understanding, data preparation, modeling, evaluation, and deployment. As the first stage, data understanding plays a pivotal role. The financial distress indicators can be basically classified into two types, indicators with financial features (Kim \& Sohn, 2010; Sanchez-Lasheras et al., 2012) and non-financial features (Wang et al., 2018). Some research reports have pointed out that the predictive ability of financial features is subject to some inherent defects. Specifically, financial features are generally homogeneous because financial ratios are calculated in the same way based on quantitative information from past data (du Jardin, 2016). Moreover, qualitative information can not be reflected from financial features although it is an important factor to represent a company's situation, such as board structure, ownership structure, retention of key personnel, and so on (Liang et al., 2016). This indicates that nonfinancial features can supplement financial features to predict financial distress. Therefore, both the financial and non-financial features are collected in the data understanding stage.

The method of financial distress prediction can usually be classified into two categories: statistical methods and machine learning methods. Statistical methods mainly include discriminant analysis (DA) (Altman, 1968; Beaver, 1966), logistic regression analysis (LOG) (Martin, 1977) and factor analysis (FA) (West, 1985). Dimitras et al. (1996) presented a review of statistical methods in predicting business failure. Logistic regression is often used in research related to financial prediction and compared with machine learning methods (Danenas \& Garsva, 2015; Cleofas-Sánchez et al., 2016; Xia et al., 2017).

The category of machine learning method is considered to be one of the latest developments in applied mathematics, which is of great significance to classification problems (Tian et al., 2012). Machine learning involves two key aspects: feature selection and model construction. Artificial intelligence tools are computer-based technologies, among which artificial neural networks (ANN) are the most commonly used bankruptcy prediction tools (Alfaro et al., 2008). Deep neural networks can extract more information from the residuals of autoregressive models and improve prediction performance (Chong et al., 2017). Olson et al. (2012) found that decision trees are relatively more accurate than neural networks and support vector machines, but there are more rule nodes than expected. Among the most improved methods, the performance of the ensemble learning method is better than many single classifiers. Barboza et al. (2017) first found that bagging, lifting, and random forest 
models are superior to other techniques, and the accuracy of all predictions in the test sample will increase when additional variables are included. In general, different classification methods show different prediction effects under different standards, and no specific algorithm is absolutely the best. In order to find a model possessing good performance, a variety of models are often compared and analyzed from empirical research in a specific environment (Alaka et al., 2017).

In a classification or prediction problem, when most instances belong to a majority class, it is called data imbalance issue. Sun et al. (2018) proposed a new DT integration model based on an imbalanced corporate credit evaluation. It integrated minority oversampling technology (SMOTE) and Bagging integrated learning with differential sampling rate (DSR) Algorithm, called decision tree integration (DTE-SBD). Zieba et al. (2016) proposed a novel bankruptcy prediction method that uses extreme gradient enhancement to learn the ensemble of decision trees. Kim et al. (2015) proposed a geometric mean-based boosting algorithm (GMBoost) to solve the problem of data imbalance. GMBoost possesses high predictive ability and strong learning ability in terms of imbalance data and balance data distribution. To solve the class-imbalance problem, we randomly sampled normal companies ten times and performed all experiments on each sample to make full use of normal company data.

Feature selection is a critical procedure for predicting financial distress. Liang et al. (2015) thought that there is no optimal solution for the combination of feature selection methods and classifiers, and the results of feature selection do not always improve prediction performance. Nevertheless, the utilization of genetic algorithm and logistic regression for feature selection can improve the prediction effects of credit and bankruptcy data sets respectively. The combination of genetic algorithms and machine learning methods are widely used in various combinatorial optimization problems (Chen et al., 2011). Genetic algorithm is proved to have good performance (Espejo et al., 2010), and a multi-objective genetic algorithm can meet different requirements in feature selection (Gorzalczany \& Rudzinski, 2016). This paper adopts the combination of genetic algorithm and random forest with the goal of high accuracy and low feature number.

Based on the above analysis, in order to improve the prediction accuracy, some practical machine learning methods in the field of prediction are used, and improvements in feature selection are also conducted. Financial and non-financial characteristics are used to characterize both quantitative and qualitative aspect of companies' status. The combination of genetic algorithm and machine learning method optimizes the fit of features. Nine models used in the following prediction are shown in Table 1, together with some related representative research papers.

\section{Research methodology}

For the financial distress prediction, statistical methods including LR, NBM, GLM, machine learning methods including SVM, NN, DT, and ensemble learning methods including RF, $\mathrm{XG}$, and $\mathrm{ADA}$ are used here. In order to achieve robustness and prevent overfitting, we adopt three different verification methods: 10 -fold cross-validation, leave-one-out cross-validation, and bootstrapping. The goal of this paper is to optimize the financial risk prediction model by dividing positive and negative companies on the basis of verifying time sensitivity. Therefore, 
Table 1. List of different models that have good performance

\begin{tabular}{|c|c|c|c|}
\hline Paper & Dataset & Techniques & Benefits \\
\hline $\begin{array}{l}\text { Heo and Yang } \\
\text { (2014) }\end{array}$ & Korea & ADA, NN, SVM, DT & $\begin{array}{l}\text { AdaBoost performs best } \\
\text { Display variable analysis } \\
\text { Modeling by company size }\end{array}$ \\
\hline $\begin{array}{l}\text { Danenas and } \\
\text { Garsva (2015) }\end{array}$ & USA (EDGAR) & SVM, NN, LR & $\begin{array}{l}\text { SVM performs best } \\
\text { Feature selection is effective }\end{array}$ \\
\hline $\begin{array}{l}\text { Cleofas-Sánchez } \\
\text { et al. (2016) }\end{array}$ & $\begin{array}{l}\text { UCI, Iran, Poland, } \\
\text { Spain, Thomas, } \\
\text { UCSD, USA }\end{array}$ & NN, SVM, LR & Different NN structures are used \\
\hline Xia et al. (2017) & $\begin{array}{l}\text { German, } \\
\text { Australian, Taiwan, } \\
\text { P2P-A, P2P-B }\end{array}$ & $\begin{array}{l}\text { LR, NN, SVM, DT, } \\
\text { Bagging, Boosting }\end{array}$ & $\begin{array}{l}\text { XGBoost is better than the baseline } \\
\text { model } \\
\text { Bayesian hyperparametric } \\
\text { optimization is used } \\
\text { Feature selection }\end{array}$ \\
\hline $\begin{array}{l}\text { Brown and } \\
\text { Mues (2012) }\end{array}$ & $\begin{array}{l}\text { German, } \\
\text { Australian, Benelux }\end{array}$ & $\begin{array}{l}\text { LOG, LDA, QDA, } \\
\text { SVM, DT, NN, GB, RF, } \\
\text { KNN }\end{array}$ & $\begin{array}{l}\text { Based on the application of } \\
\text { unbalanced data } \\
\text { RF and GB have the best } \\
\text { performance }\end{array}$ \\
\hline $\begin{array}{l}\text { Wang et al. } \\
\text { (2014) }\end{array}$ & Poland; Other & $\begin{array}{l}\text { Boosting, Bagging, DT, } \\
\text { NN, NBM, SVM, LR }\end{array}$ & $\begin{array}{l}\text { Boosting technology is improved } \\
\text { Feature selection }\end{array}$ \\
\hline $\begin{array}{l}\text { Batmaz et al. } \\
\text { (2017) }\end{array}$ & Turkey & $\begin{array}{l}\text { NN, DT, GLM, RF, } \\
\text { SVR }\end{array}$ & $\begin{array}{l}\text { The stability of GLM is slightly } \\
\text { lower than that of RF }\end{array}$ \\
\hline
\end{tabular}

Note: AdaBoost (ADA), Neural Networks (NN), Support Vector Machine (SVM), Decision Tree (DT), Linear Regression (LR), Logistic Regression (LOG), Linear Discriminant Analysis (LDA), Quadratic Discriminant Analysis (QDA), Gradient Boosting (GB), Random Forest (RF), k-Nearest Neighbours (k-NN), Naive Bayes Model (NBM), Generalized Linear Model (GLM), Support Vector Regression (SVR), XGBoost (XG).

we collect the data of the latest 3,4 , and 5 years of the companies which are labelled "ST" from 2017 to 2019. Positive and negative companies are classified according to different time windows, followed by the construction of prediction model, which is evaluated by accuracy, AUC, recall, and F1. According to the performance and percentage of different kinds of companies, the data optimization potential of well-operated companies is obtained. Through feature selection method, different indicator systems are constructed for positive companies and all companies. A three-step experiment is conducted as follows:

Experiment 1: Use data from all companies to explore the effects of financial distress prediction in different time windows.

Experiment 2: All listed companies are divided into positive and negative categories. Then, comparative experiments on these two types of companies are conducted over the results in Experiment 1 to explore the interaction between different types of companies in the prediction of financial distress.

Experiment 3: On the basis of the meaningless and poor results of the known negative company research in Experiment 2, feature selection algorithm is used to optimize and compare the positive and all companies.

Figure 1 shows a schematic diagram of the steps followed in this study. 


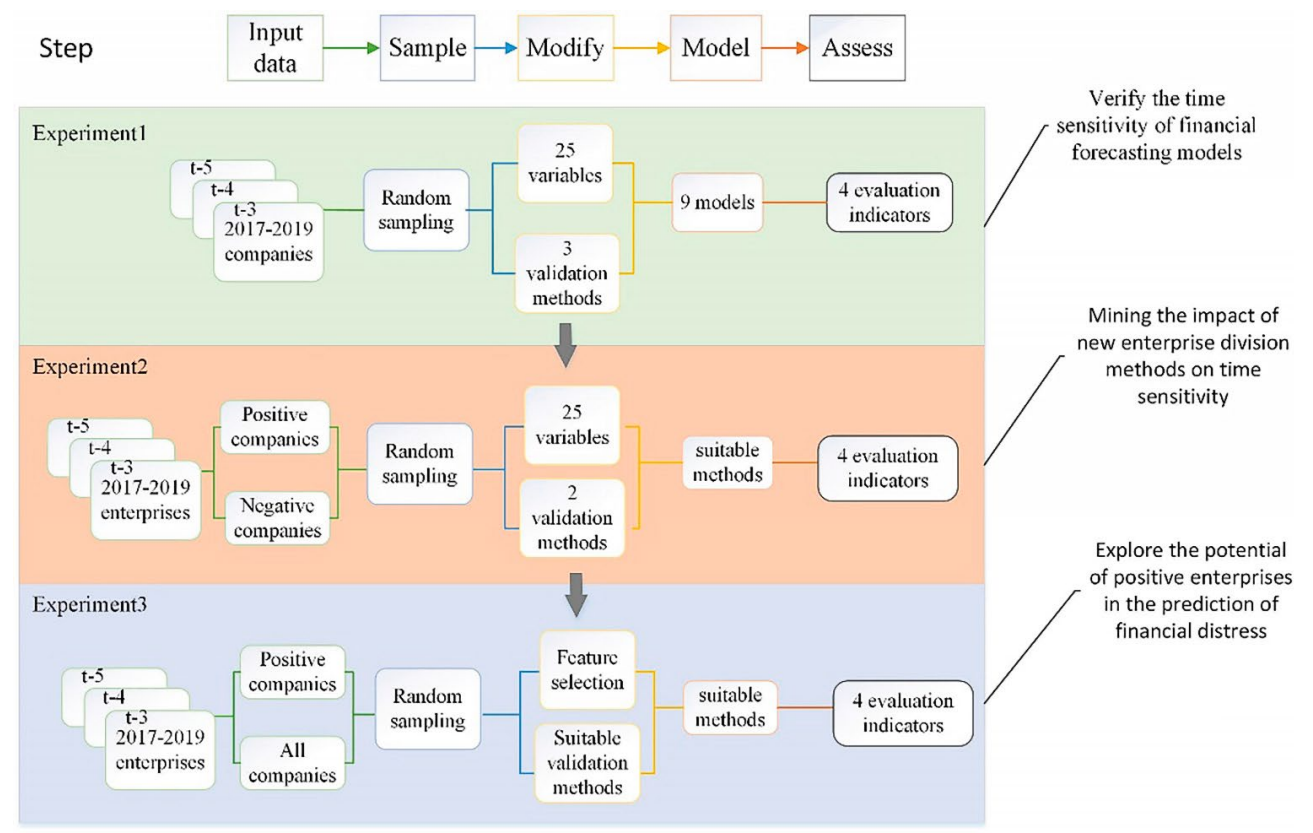

Figure 1. The procedure of the financial distress prediction

\subsection{Data collection}

\subsubsection{Data segmentation rules for positive and negative companies}

In order to resolve the interference of the mechanism that "ST label can be withdrawn" on the prediction of financial distress, we divide all listed companies into positive and negative categories. The special treatment change records of companies are obtained from the China Security Market Accounting Research (CSMAR) database. It can be found that most companies have no special treatment history. As such, in order to ensure the sample size of subsequent studies, we refer to companies that have never been warned before the time node which is the end of the selected study year as positive companies, while companies that have been labeled "ST" once or more before the node as negative companies. In other words, the classification standard we propose can be interpreted concisely as whether there has been a history of special treatment, and is not correlated with the status that whether it is currently ST. For example, if company A has no special processing records before 2019 (except for 2019) and becomes an ST company in 2019, it belongs to data with ST labeled in the positive company.

\subsubsection{Sample of financial distressed companies}

180 listed companies which were marked as ST during the period of 2017 to 2019 from the CSMAR database are selected. Generally, the reasons that these companies encountered financial difficulties are mainly caused by two years of loss, business damage, or financial bankruptcy (not including major litigation or other reasons), etc. Table 2 shows the number of listed companies that have been specially treated in the three years, including 99 positive and 81 negative companies. It is worth noting that negative companies account for $45 \%$ of ST. 
Table 2. Statistical chart of companies in financial trouble

\begin{tabular}{|l|c|c|c|c|c|}
\hline \multicolumn{1}{|c|}{ Year } & 2019 & 2018 & 2017 & Total & Proportion \\
\hline Positive & 37 & 33 & 29 & 99 & $55 \%$ \\
\hline Negative & 34 & 27 & 16 & 81 & $45 \%$ \\
\hline All & 71 & 60 & 45 & 180 & $100 \%$ \\
\hline
\end{tabular}

\subsubsection{Sample of normal companies}

In order to create a control sample that can compare the performance of financially distressed companies, 2,610 positive and non-ST companies (this type of company has never been labelled "ST" since its listing) are acquired. As shown in Table 3, 49, 66, and 66 negative and non-ST companies (these companies are currently well-operated companies but have been labelled "ST" previously) are acquired from 2017 to 2019 respectively. It is worth noting that non-ST companies account for $6.5 \%$ of negative companies.

Table 3. Statistical chart of normal companies

\begin{tabular}{|l|c|c|c|c|c|}
\hline \multicolumn{1}{|c|}{ Year } & 2019 & 2018 & 2017 & Total & Proportion \\
\hline Positive & $/$ & $/$ & $/$ & 2610 & $93.5 \%$ \\
\hline Negative & 66 & 66 & 49 & 181 & $6.5 \%$ \\
\hline All & $/$ & $/$ & $/$ & 2791 & $100 \%$ \\
\hline
\end{tabular}

\subsubsection{The time span of the data set}

Whether to obtain ST or ST* label is completely determined by its financial status in the previous two years, so it is reasonable and meaningful to implement the model based on the financial data obtained 3, 4, and 5 years before the company be labelled ST (Geng et al., 2015; Wang et al., 2014). We use different time windows to collect ST company's financial data. A 3-year time window means that $\mathrm{t}-3$ year's financial data are used to predict whether the company will be labelled as ST in year $t$. For example, if a company gets the ST label in 2019, its financial data in 2016 is to be used. Similarly, data sets based on 4-year and 5-year time windows were collected respectively.

\subsection{Indicators}

\subsubsection{Financial indicators}

According to the quantitative analysis of "Chinese Accounting Standards", we selected 21 financial indicators as input. As shown in Table 4, these indicators can be divided into four categories, which reflect the company's solvency, profitability, management capacity, and development capacity. 
Table 4. Financial indicators for distress prediction

\begin{tabular}{|c|c|c|}
\hline Types & Symbols & Formulae for calculation \\
\hline \multirow{6}{*}{ Solvency } & TL/TA & Total liabilities/total assets \\
\hline & $\mathrm{CA} / \mathrm{CL}$ & Current assets/current liabilities \\
\hline & $(\mathrm{CA}-\mathrm{I}) / \mathrm{CL}$ & (Current assets-inventory)/current liabilities \\
\hline & TL/TSE & Total liabilities/total shareholders' equity \\
\hline & $\mathrm{NOCF} / \mathrm{CL}$ & Net operating cash flow/current liabilities \\
\hline & EBIT/TL & Earnings before interest and tax (EBIT)/total liabilities \\
\hline \multirow[t]{6}{*}{ Profitability } & $(\mathrm{SR}-\mathrm{SC}) / \mathrm{SR}$ & (Sales revenue-sales cost)/sales revenue \\
\hline & NP/SR & Net profit/sales revenue \\
\hline & EBIT/ATA & Earnings before income tax/average total assets \\
\hline & NP/ATA & Net profit/average total assets \\
\hline & NP/ACA & Net profit/average current assets \\
\hline & NP/ASE & Net profit/average shareholders' equity \\
\hline \multirow{6}{*}{$\begin{array}{l}\text { Management } \\
\text { capacity }\end{array}$} & MBI/ATA & Main business income/average total assets \\
\hline & SR/ACA & Sales revenue/average current assets \\
\hline & SR/AFA & Sales revenue/average fixed assets \\
\hline & $\mathrm{MBC} / \mathrm{AI}$ & Main business cost/average inventory \\
\hline & MBI/ABAR & $\begin{array}{l}\text { Main business income/average balance of accounts } \\
\text { receivable }\end{array}$ \\
\hline & CS/APA & Cost of sales/average payable accounts \\
\hline \multirow[t]{3}{*}{$\begin{array}{l}\text { Development } \\
\text { capacity }\end{array}$} & $\begin{array}{l}\text { MBI(t)-MBI(t-1)/ } \\
\text { MBI(t-1) }\end{array}$ & $\begin{array}{l}\text { Main business income growth of this year/main } \\
\text { business income of last year }\end{array}$ \\
\hline & $\mathrm{TA}(\mathrm{t})-\mathrm{TA}(\mathrm{t}-1) / \mathrm{TA}(\mathrm{t}-1)$ & Total assets growth of this year/ /total assets of last year \\
\hline & $\mathrm{NP}(\mathrm{t})-\mathrm{NP}(\mathrm{t}-1) / \mathrm{NP}(\mathrm{t}-1)$ & Net profit growth of this year/net profit of last year \\
\hline
\end{tabular}

\subsubsection{Non-financial indicators}

Non-financial indicators such as internal control and governance structure are conducive to financial distress prediction (Liang et al., 2016; Miglani et al., 2015). As shown in Table 5, 4 non-financial indicators which reflect the company's internal control and governance structure are selected for the subsequent prediction.

Table 5. Non-financial indicators for distress prediction

\begin{tabular}{|l|l|l|}
\hline \multicolumn{1}{|c|}{ Types } & Symbols & \multicolumn{1}{c|}{ Formulae for calculation } \\
\hline Internal control & IsValid & Total liabilities/total assets \\
\hline Governance structure & NRE & Number of retired employees \\
\cline { 2 - 4 } & NBD & Number of shares held by the board of directors \\
\cline { 2 - 3 } & NDS & $\begin{array}{l}\text { Number of unpaid directors, supervisors and senior } \\
\text { executives }\end{array}$ \\
\hline
\end{tabular}




\subsection{Model}

After confirming the indicators for distress prediction, the model will be constructed which follows the well-known data mining framework CRISP-DM. Four steps are included such as: data understanding, data preparation, data modelling, and evaluation.

\subsubsection{Data understanding}

"Whether a company will receive the ST label or not" is the target variable of prediction, and it is a binary variable. "Whether the company's internal control is effective" is another binary variable. Apart from these two variables, all other input variables are continuous.

\subsubsection{Data preparation}

The data records of ST companies and normal companies are combined as the initial data set. Meanwhile, we discard normal company data with missing values. Due to the data imbalance of the initial data set, we randomly sampled normal companies ten times to make full use of the excess normal company data. We repeated all the experiments in turn for these 10 paired samples. Then, the average of ten experiments will be adopted as the final result.

As for the needs of supervised learning, we randomly partitioned the data into two parts for training and testing. The training data is used for constructing the learning models, whereas the testing data is utilized for testing the predictive ability of the models. We compared three different verification methods in order to avoid the limitations of undertraining or overtraining: 10-fold cross-validation, leave one out cross-validation (LOOCV) and bootstrapping. 10-fold cross-validation randomly splitting the overall cohort $90 \%$ and $10 \%$ into training and validation sets, and then repeating the process randomly for 10 iterations. LOOCV is used to minimize the overfitting problem (Krogh \& Vedelsby, 1995). LOOCV based approach uses only one data set for the test, and the remaining data sets are used for training. In addition, we adopt bootstrapping to avoid the problem of sample reduction caused by cross-validation through repeated sampling.

\subsubsection{Data modelling}

Some statistical, machine learning and ensemble learning algorithms are used comprehensively for data modelling. Specifically, DT, LR, NBM, SVM, NN, GLM, RF, ADA, XG are applied for the prediction of financial distress. We use Rapidminer to implement all classifiers, and the parameters of each classifier are optimized by the grid search method. The final specific parameters of each classifier are in Appendix A.

\subsubsection{Evaluation}

We measured the performance of the models in terms of their accuracy, AUC, recall, and F1 according to the commonly accepted machine learning evaluation metrics proposed by Davis and Goadrich (2006). We randomly sampled normal companies ten times to make full use of the excess normal company data. All experiments are repeated on these 10 paired samples separately and sequentially. The average predictive performance of the 10 trials is regarded as the final prediction result for each model. 


\section{Results and analysis}

\subsection{Time series analysis of all companies}

The above nine classification methods are used in Experiment 1 to make financial prediction at the three-time nodes of $\mathrm{t}-3, \mathrm{t}-4$, and $\mathrm{t}-5$, and 10 -fold cross-validation, LOOCV, and bootstrapping are employed as three comparative verification methods. Accuracy, AUC, recall, and F1 are four indicators to evaluate the experimental results, which are shown in Table 6 and Figure 2. The original data of LOOCV and bootstrapping is shown in Appendix B.

Table 6. Experimental results of different methods (All companies)

\begin{tabular}{|c|c|c|c|c|c|c|c|c|c|}
\hline & $t-3$ & & & $\mathrm{t}-4$ & & & $t-5$ & & \\
\hline \multirow{36}{*}{$\begin{array}{l}10 \text {-fold } \\
\text { cross-validation }\end{array}$} & \multirow[t]{4}{*}{ DT } & Accuracy & 0.752 & \multirow[t]{4}{*}{ DT } & Accuracy & 0.647 & \multirow[t]{4}{*}{ DT } & Accuracy & 0.589 \\
\hline & & AUC & 0.735 & & AUC & 0.628 & & AUC & 0.559 \\
\hline & & Recall & 0.739 & & Recall & 0.626 & & Recall & 0.573 \\
\hline & & F1 & 0.747 & & F1 & 0.634 & & $\mathrm{~F} 1$ & 0.577 \\
\hline & \multirow[t]{4}{*}{ LR } & Accuracy & 0.766 & \multirow[t]{4}{*}{ LR } & Accuracy & 0.629 & \multirow[t]{4}{*}{ LR } & Accuracy & 0.658 \\
\hline & & AUC & 0.800 & & AUC & 0.654 & & AUC & 0.696 \\
\hline & & Recall & 0.739 & & Recall & 0.615 & & Recall & 0.649 \\
\hline & & F1 & 0.758 & & F1 & 0.618 & & F1 & 0.653 \\
\hline & \multirow[t]{4}{*}{ NBM } & Accuracy & 0.740 & \multirow[t]{4}{*}{ NBM } & Accuracy & 0.630 & \multirow[t]{4}{*}{ NBM } & Accuracy & 0.626 \\
\hline & & AUC & 0.754 & & AUC & 0.664 & & AUC & 0.624 \\
\hline & & Recall & 0.693 & & Recall & 0.582 & & Recall & 0.554 \\
\hline & & F1 & 0.719 & & F1 & 0.590 & & F1 & 0.590 \\
\hline & \multirow[t]{4}{*}{ SVM } & Accuracy & 0.574 & \multirow[t]{4}{*}{ SVM } & Accuracy & 0.558 & \multirow[t]{4}{*}{ SVM } & Accuracy & 0.577 \\
\hline & & AUC & 0.579 & & AUC & 0.551 & & AUC & 0.580 \\
\hline & & Recall & 0.249 & & Recall & 0.232 & & Recall & 0.316 \\
\hline & & $\mathrm{F} 1$ & 0.361 & & F1 & 0.336 & & $\mathrm{~F} 1$ & 0.423 \\
\hline & \multirow[t]{4}{*}{$\mathrm{NN}$} & Accuracy & 0.763 & \multirow[t]{4}{*}{$\mathrm{NN}$} & Accuracy & 0.641 & \multirow[t]{4}{*}{$\mathrm{NN}$} & Accuracy & 0.624 \\
\hline & & AUC & 0.819 & & AUC & 0.706 & & AUC & 0.694 \\
\hline & & Recall & 0.777 & & Recall & 0.728 & & Recall & 0.748 \\
\hline & & F1 & 0.764 & & F1 & 0.667 & & F1 & 0.665 \\
\hline & \multirow[t]{4}{*}{ GLM } & Accuracy & 0.776 & \multirow[t]{4}{*}{ GLM } & Accuracy & 0.653 & \multirow[t]{4}{*}{ GLM } & Accuracy & 0.673 \\
\hline & & AUC & 0.825 & & AUC & 0.673 & & AUC & 0.724 \\
\hline & & Recall & 0.761 & & Recall & 0.668 & & Recall & 0.696 \\
\hline & & F1 & 0.772 & & F1 & 0.653 & & F1 & 0.679 \\
\hline & \multirow[t]{4}{*}{$\mathrm{RF}$} & Accuracy & 0.797 & \multirow[t]{4}{*}{$\mathrm{RF}$} & Accuracy & 0.715 & \multirow[t]{4}{*}{$\mathrm{RF}$} & Accuracy & 0.665 \\
\hline & & AUC & 0.874 & & AUC & 0.787 & & AUC & 0.718 \\
\hline & & Recall & 0.780 & & Recall & 0.704 & & Recall & 0.655 \\
\hline & & $\mathrm{F} 1$ & 0.792 & & $\mathrm{~F} 1$ & 0.708 & & F1 & 0.658 \\
\hline & \multirow[t]{4}{*}{ ADA } & Accuracy & 0.779 & \multirow[t]{4}{*}{$\mathrm{ADA}$} & Accuracy & 0.680 & \multirow[t]{4}{*}{$\mathrm{ADA}$} & Accuracy & 0.654 \\
\hline & & AUC & 0.843 & & AUC & 0.742 & & AUC & 0.706 \\
\hline & & Recall & 0.728 & & Recall & 0.622 & & Recall & 0.619 \\
\hline & & $\mathrm{F} 1$ & 0.764 & & $\mathrm{~F} 1$ & 0.653 & & $\mathrm{~F} 1$ & 0.636 \\
\hline & \multirow[t]{4}{*}{ XG } & Accuracy & 0.772 & $\mathrm{XG}$ & Accuracy & 0.705 & $\mathrm{XG}$ & Accuracy & 0.656 \\
\hline & & AUC & 0.853 & & AUC & 0.778 & & AUC & 0.712 \\
\hline & & Recall & 0.767 & & Recall & 0.702 & & Recall & 0.690 \\
\hline & & F1 & 0.769 & & F1 & 0.700 & & F1 & 0.665 \\
\hline
\end{tabular}



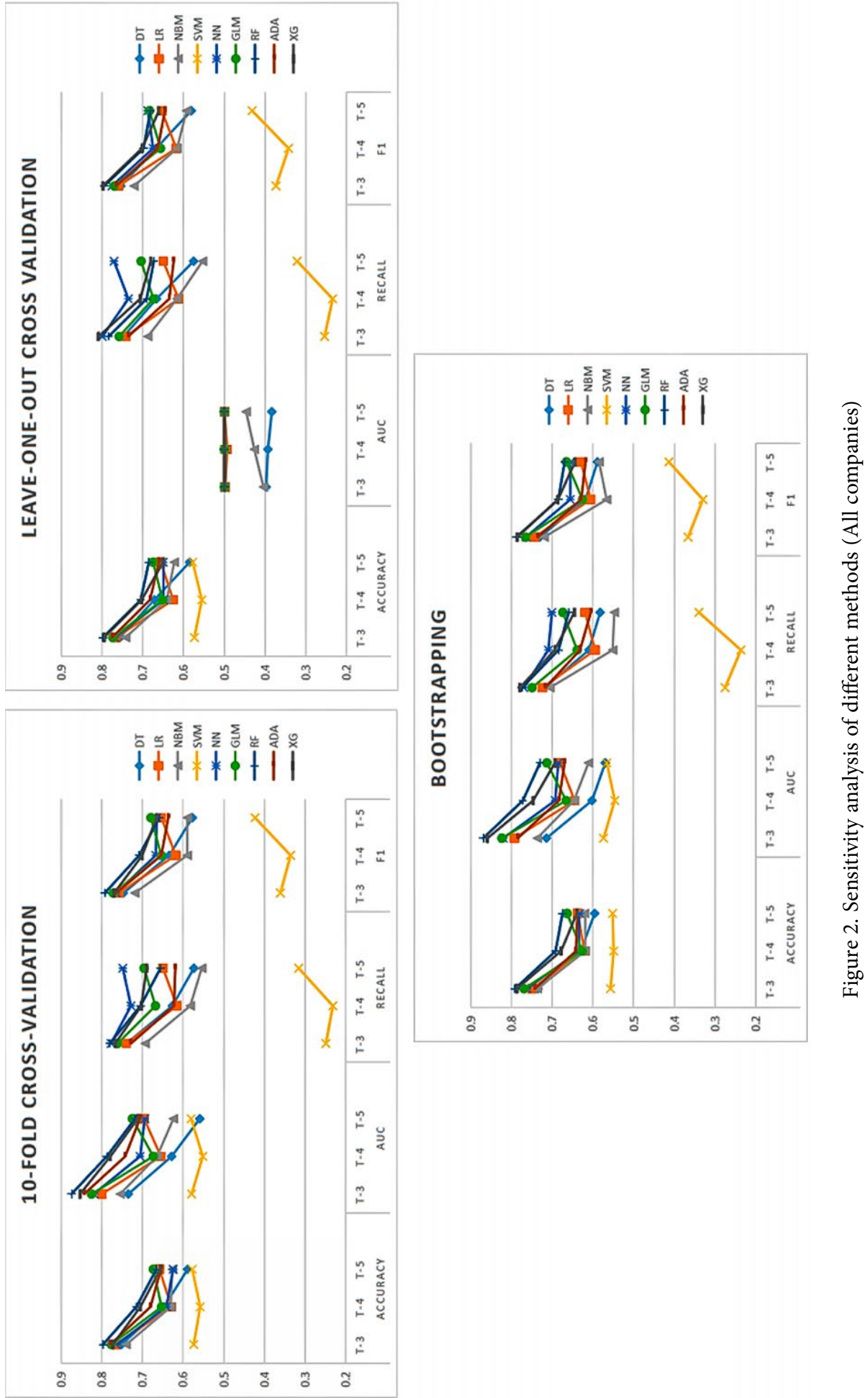
From Figure 2, it can be seen that the prediction model performs best in year t-3 (the year closest to the prediction year), and the prediction effect declines sharply in year $\mathrm{t}-4$ and continues to decrease in year t-5. All in all, experimental analysis shows that financial distress prediction is time-sensitive. Under the 10-fold cross-validation and leave-one-out crossvalidation methods, the average prediction accuracy of RF is the highest for all the three time windows, followed by the XG. This is similar to the result of Mousavi and Lin (2020). Under the bootstrapping method, the performance of XG is slightly higher than the performance of RF. In general, the five classification algorithms such that NN, GLM, RF, ADA, and XG perform better, while the recall value of SVM is extremely low. The performances of SVM and NBM are the worst in all cases. In summary, Experiment 1 verifies the difference in the prediction effects of all companies under different time windows. In addition, in the LOOCV scheme, the test sample is always only an instance, so AUC cannot be calculated.

\subsection{Comparative analysis of positive and negative companies}

In order to explore the internal laws between positive and negative companies, comparative analysis is conducted in experiment 2 . The prediction performance of NN, GLM, RF, ADA, and XG models are shown in Tables 7 and 8 . Since the LOOCV scheme cannot use the AUC indicator for evaluation, it will not be used in Experiment 2. The data of bootstrapping is in Appendix C.

Table 7. Experimental results of different methods (Positive companies)

\begin{tabular}{|c|c|c|c|c|c|c|c|c|c|}
\hline & $t-3$ & & & $\mathrm{t}-4$ & & & $t-5$ & & \\
\hline \multirow{20}{*}{$\begin{array}{l}10 \text {-fold } \\
\text { cross-validation }\end{array}$} & \multirow[t]{4}{*}{$\mathrm{NN}$} & Accuracy & 0.762 & \multirow[t]{4}{*}{ NN } & Accuracy & 0.670 & \multirow[t]{4}{*}{ NN } & Accuracy & 0.648 \\
\hline & & AUC & 0.821 & & AUC & 0.743 & & AUC & 0.703 \\
\hline & & Recall & 0.759 & & Recall & 0.715 & & Recall & 0.752 \\
\hline & & F1 & 0.759 & & F1 & 0.677 & & F1 & 0.678 \\
\hline & \multirow[t]{4}{*}{ GLM } & Accuracy & 0.783 & \multirow[t]{4}{*}{ GLM } & Accuracy & 0.685 & \multirow[t]{4}{*}{ GLM } & Accuracy & 0.671 \\
\hline & & AUC & 0.837 & & AUC & 0.737 & & AUC & 0.692 \\
\hline & & Recall & 0.734 & & Recall & 0.721 & & Recall & 0.646 \\
\hline & & F1 & 0.767 & & F1 & 0.693 & & F1 & 0.653 \\
\hline & \multirow[t]{4}{*}{$\mathrm{RF}$} & Accuracy & 0.804 & \multirow[t]{4}{*}{$\mathrm{RF}$} & Accuracy & 0.718 & \multirow[t]{4}{*}{$\mathrm{RF}$} & Accuracy & 0.672 \\
\hline & & AUC & 0.879 & & AUC & 0.783 & & AUC & 0.732 \\
\hline & & Recall & 0.728 & & Recall & 0.703 & & Recall & 0.636 \\
\hline & & F1 & 0.786 & & F1 & 0.714 & & F1 & 0.656 \\
\hline & \multirow[t]{4}{*}{$\mathrm{ADA}$} & Accuracy & 0.788 & \multirow[t]{4}{*}{ ADA } & Accuracy & 0.710 & \multirow[t]{4}{*}{$\mathrm{ADA}$} & Accuracy & 0.651 \\
\hline & & AUC & 0.832 & & AUC & 0.742 & & AUC & 0.700 \\
\hline & & Recall & 0.697 & & Recall & 0.638 & & Recall & 0.609 \\
\hline & & F1 & 0.753 & & F1 & 0.672 & & F1 & 0.630 \\
\hline & \multirow[t]{4}{*}{$\mathrm{XG}$} & Accuracy & 0.778 & \multirow[t]{4}{*}{ XG } & Accuracy & 0.698 & \multirow[t]{4}{*}{ XG } & Accuracy & 0.677 \\
\hline & & AUC & 0.849 & & AUC & 0.767 & & AUC & 0.732 \\
\hline & & Recall & 0.765 & & Recall & 0.694 & & Recall & 0.649 \\
\hline & & F1 & 0.772 & & F1 & 0.685 & & F1 & 0.665 \\
\hline
\end{tabular}


Table 8. Experimental results of different methods (Negative companies)

\begin{tabular}{|c|c|c|c|c|c|c|c|c|c|}
\hline & $t-3$ & & & $\mathrm{t}-4$ & & & $t-5$ & & \\
\hline \multirow{20}{*}{$\begin{array}{l}10 \text {-fold } \\
\text { cross-validation }\end{array}$} & \multirow[t]{4}{*}{ NN } & Accuracy & 0.588 & \multirow[t]{4}{*}{ NN } & Accuracy & 0.735 & \multirow[t]{4}{*}{ NN } & Accuracy & 0.524 \\
\hline & & AUC & 0.613 & & AUC & 0.770 & & AUC & 0.528 \\
\hline & & Recall & 0.643 & & Recall & 0.722 & & Recall & 0.600 \\
\hline & & $\mathrm{F} 1$ & 0.578 & & $\mathrm{~F} 1$ & 0.705 & & $\mathrm{~F} 1$ & 0.526 \\
\hline & \multirow[t]{4}{*}{ GLM } & Accuracy & 0.598 & \multirow[t]{4}{*}{ GLM } & Accuracy & 0.729 & \multirow[t]{4}{*}{ GLM } & Accuracy & 0.555 \\
\hline & & AUC & 0.607 & & AUC & 0.796 & & AUC & 0.556 \\
\hline & & Recall & 0.439 & & Recall & 0.515 & & Recall & 0.395 \\
\hline & & $\mathrm{F} 1$ & 0.490 & & F1 & 0.613 & & F1 & 0.438 \\
\hline & \multirow[t]{4}{*}{$\mathrm{RF}$} & Accuracy & 0.588 & \multirow[t]{4}{*}{$\mathrm{RF}$} & Accuracy & 0.825 & \multirow[t]{4}{*}{$\mathrm{RF}$} & Accuracy & 0.556 \\
\hline & & AUC & 0.617 & & AUC & 0.862 & & AUC & 0.586 \\
\hline & & Recall & 0.469 & & Recall & 0.770 & & Recall & 0.471 \\
\hline & & F1 & 0.498 & & F1 & 0.793 & & F1 & 0.482 \\
\hline & \multirow[t]{4}{*}{$\mathrm{ADA}$} & Accuracy & 0.574 & \multirow[t]{4}{*}{ ADA } & Accuracy & 0.798 & \multirow[t]{4}{*}{$\mathrm{ADA}$} & Accuracy & 0.559 \\
\hline & & AUC & 0.574 & & AUC & 0.818 & & AUC & 0.574 \\
\hline & & Recall & 0.364 & & Recall & 0.721 & & Recall & 0.396 \\
\hline & & $\mathrm{F} 1$ & 0.423 & & $\mathrm{~F} 1$ & 0.755 & & $\mathrm{~F} 1$ & 0.431 \\
\hline & \multirow[t]{4}{*}{ XG } & Accuracy & 0.598 & \multirow[t]{4}{*}{$\mathrm{XG}$} & Accuracy & 0.729 & \multirow[t]{4}{*}{$X G$} & Accuracy & 0.555 \\
\hline & & AUC & 0.607 & & AUC & 0.796 & & AUC & 0.556 \\
\hline & & Recall & 0.439 & & Recall & 0.515 & & Recall & 0.395 \\
\hline & & $\mathrm{F} 1$ & 0.490 & & $\mathrm{~F} 1$ & 0.613 & & F1 & 0.438 \\
\hline
\end{tabular}

In order to see the results more intuitively, Figure 3 only reports accuracy, a measure of predictive performance, because the other three perform basically the same as accuracy, and experiment 1 shows that accuracy performance is more concentrated and stable.

Obviously, the prediction results of all methods perform best in $\mathrm{t}-3$. The results of $\mathrm{NN}$ in $\mathrm{t}-4$ and $\mathrm{t}-5$ are similar, and the results of GLM in $\mathrm{t}-5$ are better than $\mathrm{t}-4$. The results of the ensemble learning algorithm are basically similar, and the RF performs better. The two verification methods have little effect on the experimental results, and the 10-fold cross-validation performance is more stable in comparison. With respect to Experiment 1 and 2, although the results of positive and all companies have the same trend in time series, positive companies are slightly better than all companies. Although negative companies are worse than all companies in $\mathrm{t}-3$ and $\mathrm{t}-5$ years, their outstanding performance in $\mathrm{t}-4$ year may be caused by the fact that negative companies falsified financial data except when they are required to be disclosed. Although the ratio of negative companies in ST companies is $45 \%$ (this is also the reason that affects the predictive effect of all companies), negative companies only account for $8.81 \%$ in the total sample which composed of ST and normal companies. Comparatively, positive companies accounted for $91.19 \%$ of all companies. In summary, negative companies exhibit three characteristics: small sample size, inconsistent laws, and adverse effect to the total sample. Therefore, instead of exploring negative companies in depth, the financial distress 

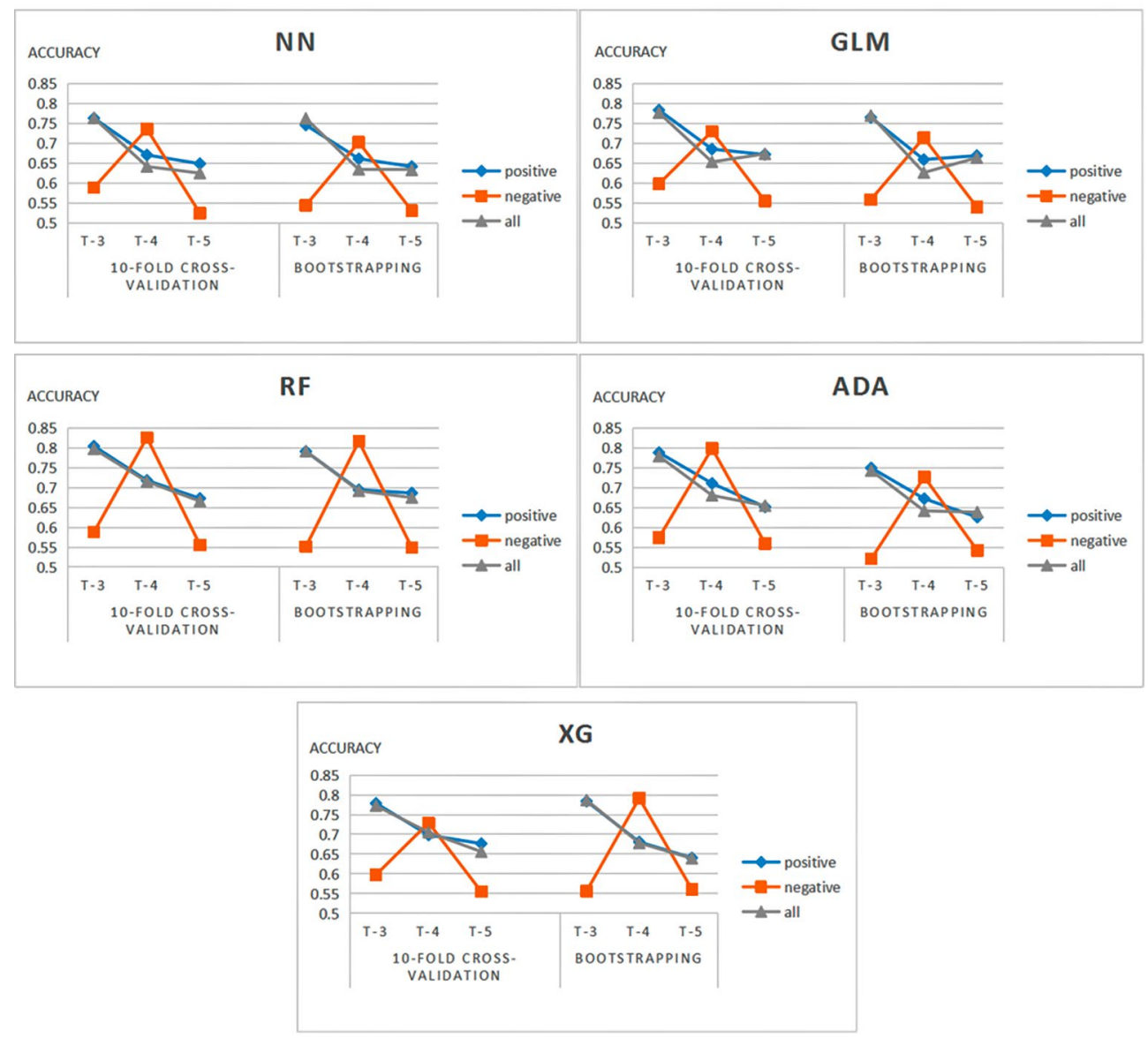

Figure 3. Sensitivity analysis of different methods (Three kinds of company)

prediction of positive companies is more meaningful, and the data optimization of positive companies has more potential. Next, feature selection will be conducted on both positive companies and all companies. In order to highlight the experimental results, random forest model and 10-fold cross-validation is to be utilized in the following experiments.

\subsection{Feature importance analysis}

The wrapper based methods of the genetic algorithm (GA) is widely used in feature selection (Yu \& Cho, 2006), the Multi-Objective Genetic Algorithm (MOGA) is a variation of the classical GA and performs well in feature selection (Das et al., 2017; Gorzalczany \& Rudzinski, 2016; Dutta et al., 2020). This technique addresses the search toward the true Pareto front while maintaining diversity in the population (Konak et al., 2006). We will adopt a multiobjective wrapper based on a genetic algorithm. It uses a non-dominant sorting selection method to minimize the number of features and maximize accuracy. It will help us to find the difference between the feature set of positive companies and all companies, and improve 
the performance of the classifier. Random forest and 10-fold cross-validation perform better, so we will use these two methods in the wrapper. In the multi-objective feature selection method, we set the number of iteration terminations to be 100 , and the number of individuals in each generation is 20 (an individual is a running result represented by a set of features). We conducted six sets of experiments (namely, the feature selection of positive companies on $\mathrm{t}-3, \mathrm{t}-4$, and $\mathrm{t}-5$ and the feature selection of all companies on $\mathrm{t}-3, \mathrm{t}-4$, and $\mathrm{t}-5$ ), in which 10 random samplings are used. The best-performing individual is selected from the 20 individuals obtained from the experimental results of each sample to represent the prediction effect of this sample. Table 9 shows the results of six groups of experiments. The data of each group of experiments are calculated by averaging the results of ten random samples. The specific data are in Appendix D.

Table 9. Experimental results of feature selection (Positive companies and all companies)

\begin{tabular}{|l|c|c|c|c|c|c|c|c|c|}
\hline & $\mathrm{t}-3$ & & $\begin{array}{c}\text { Change } \\
(\%)\end{array}$ & $\mathrm{t}-4$ & & $\begin{array}{c}\text { Change } \\
(\%)\end{array}$ & $\mathrm{t}-5$ & & $\begin{array}{c}\text { Change } \\
(\%)\end{array}$ \\
\hline \multirow{4}{*}{ Positive } & Accuracy & 0.879 & 7.5 & Accuracy & 0.791 & 7.3 & Accuracy & 0.753 & 8.3 \\
\cline { 2 - 12 } & AUC & 0.901 & 2.2 & AUC & 0.811 & 2.8 & AUC & 0.770 & 3.8 \\
\cline { 2 - 12 } & Recall & 0.852 & 12.4 & Recall & 0.773 & 7.0 & Recall & 0.741 & 10.5 \\
\cline { 2 - 12 } & F1 & 0.873 & 8.7 & F1 & 0.786 & 7.2 & F1 & 0.748 & 9.2 \\
\hline \hline \multirow{4}{*}{ All } & Accuracy & 0.843 & 4.6 & Accuracy & 0.762 & 4.7 & Accuracy & 0.726 & 6.1 \\
\cline { 2 - 11 } & AUC & 0.910 & 3.6 & AUC & 0.831 & 4.4 & AUC & 0.793 & 7.5 \\
\cline { 2 - 11 } & Recall & 0.861 & 8.1 & Recall & 0.795 & 9.1 & Recall & 0.752 & 9.7 \\
\cline { 2 - 11 } & F1 & 0.845 & 5.3 & F1 & 0.768 & 6.0 & F1 & 0.731 & 7.3 \\
\hline
\end{tabular}

After feature selection, the prediction effects for the two types of companies have been improved in each year, among which the extent of positive companies are more obvious. In the year of $t-3, t-4$, and $t-5$, the accuracy of positive companies is about $2.5 \%$ higher than that of all companies, which verifies the potential prediction ability of positive companies. With respect to F1 scores, positive companies also have better performance.

In addition, we mix ten randomly sampled result feature sets of each experiment, calculate the frequency of each feature in the mixed set, and rank the feature importance according to the frequency. The difference between the indicator systems of these two types of companies is explored by comparing the feature importance rankings of them. The results are shown in Table 10.

We have observed that the top 10 important characteristics of positive companies in different years are quite different, that is, different years focus on different characteristics. For example, $t-3$ focuses on the characteristics of development ability $(\mathrm{NP}(\mathrm{t})-\mathrm{NP}(\mathrm{t}-1) / \mathrm{NP}(\mathrm{t}-1)$, $\operatorname{MBI}(t)-\operatorname{MBI}(\mathrm{t}-1) / \mathrm{MBI}(\mathrm{t}-1))$ and profitability (NP/ATA, NP/ACA), while $t-4$ focuses on the characteristics of solvency ((CA-I)/CL). In contrast, the difference for the top 10 important characteristics of all companies in different years is not obvious, although some differences are really observed in the order of importance. In addition, we found that the growth of the total assets of $\mathrm{TA}(\mathrm{t})-\mathrm{TA}(\mathrm{t}-1) / \mathrm{TA}(\mathrm{t}-1)$ performed well in all experimental groups, which shows the importance of its development ability to predict financial distress. 
Table 10. Top 10 indicators of importance for positive and all companies

\begin{tabular}{|c|c|c|c|c|c|c|}
\hline \multirow{2}{*}{ Number } & Positive & & & All & & \\
\hline & $t-3$ & $\mathrm{t}-4$ & $t-5$ & $t-3$ & $\mathrm{t}-4$ & $t-5$ \\
\hline 1 & $\begin{array}{l}\mathrm{NP}(\mathrm{t})- \\
\mathrm{NP}(\mathrm{t}-1) / \\
\mathrm{NP}(\mathrm{t}-1)\end{array}$ & $(\mathrm{CA}-\mathrm{I}) / \mathrm{CL}$ & SR/AFA & $\begin{array}{l}\mathrm{NP}(\mathrm{t})- \\
\mathrm{NP}(\mathrm{t}-1) / \\
\mathrm{NP}(\mathrm{t}-1)\end{array}$ & $(\mathrm{CA}-\mathrm{I}) / \mathrm{CL}$ & NBD \\
\hline 2 & NDS & $\mathrm{MBC} / \mathrm{AI}$ & $\begin{array}{l}\mathrm{NP}(\mathrm{t})- \\
\mathrm{NP}(\mathrm{t}-1) / \\
\mathrm{NP}(\mathrm{t}-1)\end{array}$ & $\begin{array}{c}\text { TA(t)- } \\
\text { TA(t-1)/ } \\
\text { TA(t-1) }\end{array}$ & SR/AFA & NRE \\
\hline 3 & $\begin{array}{c}\text { MBI(t)- } \\
\operatorname{MBI}(\mathrm{t}-1) / \\
\mathrm{MBI}(\mathrm{t}-1)\end{array}$ & NDS & NDS & SR/AFA & $\mathrm{NOCF} / \mathrm{CL}$ & TL/TA \\
\hline 4 & NRE & SR/ACA & NP/ACA & NBD & NP/ACA & NP/ATA \\
\hline 5 & $\begin{array}{c}\text { TA(t)- } \\
\text { TA(t-1)/ } \\
\text { TA(t-1) }\end{array}$ & $\begin{array}{l}\text { TA(t)- } \\
\text { TA(t-1)/ } \\
\text { TA(t-1) }\end{array}$ & NBD & NOCF/CL & $\begin{array}{c}\text { TA(t)- } \\
\text { TA(t-1)/ } \\
\text { TA(t-1) }\end{array}$ & $(\mathrm{SR}-\mathrm{SC}) / \mathrm{SR}$ \\
\hline 6 & NP/ATA & NOCF/CL & TL/TA & $\mathrm{MBC} / \mathrm{AI}$ & NDS & $\begin{array}{c}\text { TA(t)- } \\
\text { TA(t-1)/ } \\
\text { TA(t-1) }\end{array}$ \\
\hline 7 & NP/ACA & TL/TSE & $\mathrm{MBC} / \mathrm{AI}$ & CS/APA & MBI/ABAR & $\begin{array}{l}\mathrm{NP}(\mathrm{t})- \\
\mathrm{NP}(\mathrm{t}-1) / \\
\mathrm{NP}(\mathrm{t}-1)\end{array}$ \\
\hline 8 & NP/ASE & SR/AFA & NP/ASE & NRE & $(\mathrm{SR}-\mathrm{SC}) / \mathrm{SR}$ & TL/TSE \\
\hline 9 & (SR-SC)/SR & MBI/ATA & $\begin{array}{l}\text { TA(t)- } \\
\text { TA(t-1)/ } \\
\text { TA(t-1) }\end{array}$ & EBIT/TL & NBD & SR/AFA \\
\hline 10 & MBI/ABAR & $(\mathrm{SR}-\mathrm{SC}) / \mathrm{SR}$ & $\begin{array}{c}\text { MBI(t)- } \\
\text { MBI(t-1)/ } \\
\text { MBI(t-1) }\end{array}$ & NDS & NRE & EBIT/ATA \\
\hline
\end{tabular}

In order to show the difference between the indicator systems for these two kinds of company more intuitively, we also counted the distribution of the feature types for these six groups of experiments. The number of occurrences of each feature in each group of experiments is calculated according to development capacity, management capacity, profitability, solvency, and Non-financial indicators (indicating internal control and corporate governance). Some rules are found in this comparison, and the results are shown in Figure 4.

Positive companies focused on development capabilities and profitability in $t-3$, while focused on solvency and management capacity in $t-4$, which demonstrates that positive companies have different preferences in different years. Moreover, positive companies are more focused in all years, that is, the feature of each year are more concentrated in one or two aspects, which also leads to better prediction effects. However, the difference among the optimal feature sets of all companies in different years is small. They are mainly concentrated in management capacity, solvency, and profitability, and are more balanced than benign companies. 


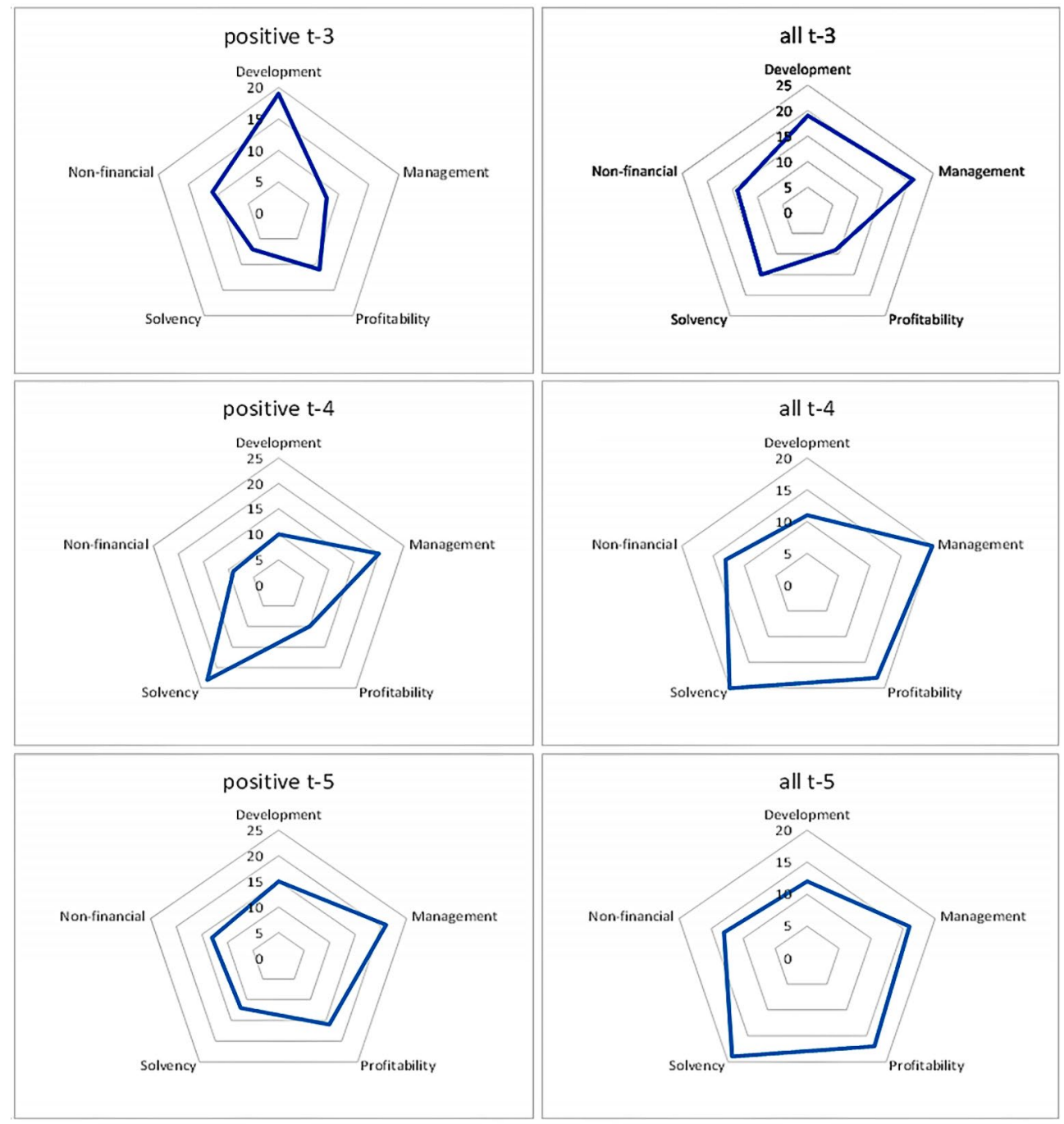

Figure 4. Comparison of indicator systems for positive and all companies

In conclusion, we used the multi-objective feature selection method to optimize positive companies and all companies, which makes the prediction effect of the model better. Among them, the effect of positive company optimization is more obvious, which can identify more stable and high-quality investment projects for investors. In addition, we ranked the importance of features of positive companies and all companies to verify the difference between the feature preferences of the two. This will help investors judge the true financial status of different types of companies in different years, and provide a basis for constructing different characteristic systems for different types of companies in the future. 


\section{Conclusions and discussions}

In this paper, we proposed a data segmentation approach based on the number of times being labeled ST and make financial distress prediction for positive, negative, and all companies. In the time series, the model is optimized through the division of company types and feature selection. The main contributions of this paper are shown as follows:

Considering the sample size, we selected all companies that were specially treated during 2017-2019 as the ST company sample. The results of 10 repeated random sampling verification and the use of different verification methods solved the problem of data imbalance and enhanced the reliability of the results. The prediction abilities of indicators in t-3, t-4 and $\mathrm{t}-5$ years are compared to find that the prediction effect deteriorates with the time series. Through the division of company types, we find that the results of negative companies in $t-3$ and $\mathrm{t}-5$ are worse than those of positive companies and all companies, and the best predictive effect is obtained in $\mathrm{t}-4$. The uncertainty of negative companies may mean that they falsified financial data except when required to be disclosed. Positive companies show the same rules as all companies, they have obtained the best prediction results in $\mathrm{t}-3$ years and deteriorated over time. At the same time, positive companies have shown better predictive effects than the other two types in each year except for the results of negative companies in $t-4$. Since negative companies exhibit three characteristics including small sample size, inconsistent laws, and large damage to the total sample, we don't explore negative companies in depth. We believe that the financial distress prediction of positive companies is more meaningful and their data optimization has more potential. In order to reflect the optimization potential of positive companies, the prediction results of positive companies and all companies are compared through feature selection. By comparison, we found that the optimization potential of positive companies is greater than that of all companies, and their features preference is more obvious in the time series, while the performance of all companies is more balanced. In summary, we analyzed the deterioration of financial prediction in time series and constructed an optimization model for positive companies.

Based on the research results of this paper, we provide investors with a new model to determine the company's financial status. That is, investors select positive companies according to the ST times of each company, and then predict their financial status through the company's characteristic preferences in different years. Investors will get more stable and high-quality investment objects, which reduce investment risks.

Regarding the special performance of negative companies in the time series, we can explore the reasons for their outstanding prediction effect in t-4 years, and then add more influential non-financial features for the purpose to improve the financial prediction effect of such companies. In addition, using special treatment change records to create new feature variables is an important research direction, because it represents credibility in China's institutional system. The dynamic relationship among positive, negative, and all companies together with the different sensitivity of the three to features are very important for the financial distress prediction of Chinese listed companies. Future research may focus on other differences among the three to establish models and conduct comparisons. 


\section{Acknowledgements}

This research is supported by the Philosophy and Social Sciences Planning Youth Project of Anhui Province (AHSKQ2019D020) and the NSFC-Zhejiang Joint Fund for the Integration of Industrialization and Informatization under the Grant (No. U1709215).

\section{References}

Alaka, H. A., Oyedele, L. O., Owolabi, H. A., Kumar, V., Ajayi, S. O., Akinade, O. O., \& Bilal, M. (2017). Systematic review of bankruptcy prediction models: Towards a framework for tool selection. Expert Systems with Application, 94, 164-184. https://doi.org/10.1016/j.eswa.2017.10.040

Alfaro, E., Garcia, N., Gamez, M., \& Elizondo, D. (2008). Bankruptcy forecasting: An empirical comparison of AdaBoost and neural networks. Decision Support Systems, 45(1), 110-122. https://doi.org/10.1016/j.dss.2007.12.002

Altman, E. I. (1968). Financial ratios, discriminant analysis and the prediction of corporate bankruptcy. The Journal of Finance, 23(4), 589-609. https://doi.org/10.1111/j.1540-6261.1968.tb00843.x

Barboza, F., Kimura, H., \& Altman, E. (2017). Machine learning models and bankruptcy prediction. Expert Systems with Applications, 83, 405-417. https://doi.org/10.1016/j.eswa.2017.04.006

Batmaz, I., Danisoglu, S., Yazici, C., \& Kartal-Koc, E. (2017). A data mining application to deposit pricing: Main determinants and prediction models. Applied Soft Computing, 60, 808-819. https://doi.org/10.1016/j.asoc.2017.07.047

Beaver, W. H. (1966). Financial ratios as predictors of failure. Journal of Accounting Research, 4, 71-111. https://doi.org/10.2307/2490171

Brown, I., \& Mues, C. (2012). An experimental comparison of classification algorithms for imbalanced credit scoring data sets. Expert Systems with Applications, 39, 3446-3453. https://doi.org/10.1016/j.eswa.2011.09.033

Chen, N., Ribeiro, B., Vieira, A. S., Duarte, J., \& Neves, J. C. (2011). A genetic algorithm-based approach to cost-sensitive bankruptcy prediction. Expert Systems with Applications, 38, 12939-12945. https://doi.org/10.1016/j.eswa.2011.04.090

Chong, E., Han, C., \& Park, F. C. (2017). Deep learning networks for stock market analysis and prediction: Methodology, data representations, and case studies. Expert Systems with Applications, 83, 187-205. https://doi.org/10.1016/j.eswa.2017.04.030

Cleofas-Sánchez, L., García, V., Marqués, A., \& Sénchez, J. (2016). Financial distress prediction using the hybrid associative memory with translation. Applied Soft Computing, 44, 144-152. https://doi.org/10.1016/j.asoc.2016.04.005

Danenas, P., \& Garsva, G. (2015). Selection of support vector machines based classifiers for credit risk domain. Expert Systems with Applications, 42(6), 3194-3204. https://doi.org/10.1016/j.eswa.2014.12.001

Das, A. K., Das, S., \& Ghosh, A. (2017). Ensemble feature selection using bi-objective genetic algorithm. Knowledge-Based Systems, 123, 116-127. https://doi.org/10.1016/j.knosys.2017.02.013

Davis, J., \& Goadrich, M. (2006). The relationship between precision-recall and ROC curves. In Proceedings of the 23rd International Conference on Machine Learning (pp. 233-240). Association for Computing Machinery. https://doi.org/10.1145/1143844.1143874

Dimitras, A. I., Zanakis, S. H., \& Zopounidis, C. (1996). A survey of business failures with an emphasis on prediction methods and industrial applications. European Journal of Operational Research, 90(3), 487-513. https://doi.org/10.1016/0377-2217(95)00070-4 
Ding, Y. S., Song, X. P., \& Zen, Y. M. (2008). Forecasting financial condition of Chinese listed companies based on support vector machine. Expert Systems with Applications, 34(4), 3081-3089. https://doi.org/10.1016/j.eswa.2007.06.037

du Jardin, P. (2016). A two-stage classification technique for bankruptcy prediction. European Journal of Operational Research, 254(1), 236-252. https://doi.org/10.1016/j.ejor.2016.03.008

Dutta, D., Sil, J., \& Dutta, P. (2020). A bi-phased multi-objective genetic algorithm based classifier. Expert Systems with Applications, 146, 113163. https://doi.org/10.1016/j.eswa.2019.113163

Espejo, P. G., Ventura, S., \& Herrera, F. (2010). A survey on the application of genetic programming to classification. IEEE Transactions on Systems Man and Cybernetics Part C (Applications and Reviews), 40(2), 121-144. https://doi.org/10.1109/TSMCC.2009.2033566

Farisha, H., Hafiza, A. H., \& Zalailah, S. (2012). Motivation for earnings management among auditors in Malaysia. Procedia - Social and Behavioral Sciences, 65, 239-246.

https://doi.org/10.1016/j.sbspro.2012.11.117

Geng, R. B., Bose, I., \& Chen, X. (2015). Prediction of financial distress: An empirical study of listed Chinese companies using data mining. European Journal of Operational Research, 241(1), 236-247. https://doi.org/10.1016/j.ejor.2014.08.016

Gorzalczany, M. B., \& Rudzinski, F. (2016). A multi-objective genetic optimization for fast, fuzzy rulebased credit classification with balanced accuracy and interpretability. Applied Soft Computing, 40, 206-220. https://doi.org/10.1016/j.asoc.2015.11.037

Heo, J., \& Yang, J. Y. (2014). AdaBoost based bankruptcy forecasting of Korean construction companies. Applied Soft Computing, 24, 494-499. https://doi.org/10.1016/j.asoc.2014.08.009

Yu, E. Z., \& Cho, S. (2006). Ensemble based on GA wrapper feature selection. Computers \& Industrial Engineering, 51(1), 111-116. https://doi.org/10.1016/j.cie.2006.07.004

Kim, H. S., \& Sohn, S. Y. (2010). Support vector machines for default prediction of SMEs based on technology credit. European Journal of Operational Research, 201, 838-846.

https://doi.org/10.1016/j.ejor.2009.03.036

Kim, M. J., Kang, D. K., \& Kim, H. B. (2015). Geometric mean based boosting algorithm with oversampling to resolve data imbalance problem for bankruptcy prediction. Expert Systems with Applications, 42(3), 1074-1082. https://doi.org/10.1016/j.eswa.2014.08.025

Konak, A., Coit, D. W., \& Smith, A. E. (2006). Multi-objective optimization using genetic algorithms: A tutorial. Reliability Engineering and System Safety, 91(9), 992-1007. https://doi.org/10.1016/j.ress.2005.11.018

Krogh, A., \& Vedelsby, J. (1995). Neural network ensembles, cross validation, and active learning. Advances in Neural Information Processing Systems, 7, 231-238.

Liang, D., Lu, C. C., Tsai, C. F., \& Shih, G. A. (2016). Financial ratios and corporate governance indicators in bankruptcy prediction: A comprehensive study. European Journal of Operational Research, 252(2), 561-572. https://doi.org/10.1016/j.ejor.2016.01.012

Liang, D., Tsai, C. F., \& Wu, H. T. (2015). The effect of feature selection on financial distress prediction. Knowledge-Based Systems, 73, 289-297. https://doi.org/10.1016/j.knosys.2014.10.010

Lin, W. Y., Hu, Y. H., \& Tsai, C. F. (2012). Machine learning in financial crisis prediction: A survey. IEEE Transactions on Systems Man and Cybernetics Part C (Applications and Reviews), 42(4), 421-436. https://doi.org/10.1109/TSMCC.2011.2170420

Martin, D. (1977). Early warnings of bank failure: A logit regression approach. Journal of Banking and Finance, 1(3), 249-276. https://doi.org/10.1016/0378-4266(77)90022-X

Miglani, S., Ahmed, K., \& Henry, D. (2015). Voluntary corporate governance structure and financial distress: Evidence from Australia. Journal of Contemporary Accounting \& Economics, 11(1), 18-30. https://doi.org/10.1016/j.jcae.2014.12.005 
Mousavi, M. M., \& Lin, J. L. (2020). The application of PROMETHEE multi-criteria decision aid in financial decision making: Case of distress prediction models evaluation. Expert Systems with Applications, 159, 113438. https://doi.org/10.1016/j.eswa.2020.113438

Olson, D. L., Delen, D., \& Meng, Y. Y. (2012). Comparative analysis of data mining methods for bankruptcy prediction. Decision Support Systems, 52(2), 464-473. https://doi.org/10.1016/j.dss.2011.10.007

Sanchez-Lasheras, F., de Andres, J., Lorca, P., \& de Cos Juez, F. J. (2012). A hybrid device for the solution of sampling bias problems in the forecasting of firms' bankruptcy. Expert Systems with Applications, 39, 7512-7523. https://doi.org/10.1016/j.eswa.2012.01.135

Shearer, C. (2000). The CRISP-DM model: The new blueprint for data mining. Journal of Data Warehousing, 5(4), 3-22.

Sun, J., Lang, J., Fujita, H., \& Li, H. (2018). Imbalanced enterprise credit evaluation with DTE-SBD: Decision tree ensemble based on SMOTE and bagging with differentiated sampling rates. Information Sciences, 425, 76-91. https://doi.org/10.1016/j.ins.2017.10.017

Sun, J., Li, H., Fujita, H., Fu, B. B., \& Ai, W. G. (2020). Class-imbalanced dynamic financial distress prediction based on Adaboost-SVM ensemble combined with SMOTE and time weighting. Information Fusion, 54, 128-144. https://doi.org/10.1016/j.inffus.2019.07.006

Tian, Y., Shi, Y., \& Liu, X. (2012). Recent advances on support vector machines research. Technological and Economic Development of Economy, 18(1), 5-33. https://doi.org/10.3846/20294913.2012.661205

Wang, G., Chen, G., \& Chu, Y. (2018). A new random subspace method incorporating sentiment and textual information for financial distress prediction. Electronic Commerce Research and Applications, 29, 30-49. https://doi.org/10.1016/j.elerap.2018.03.004

Wang, G., Ma, J. L., Chen, G., \& Yang, Y. (2020). Financial distress prediction: Regularized sparse-based Random Subspace with ER aggregation rule incorporating textual disclosures. Applied Soft Computing, 90, 106152. https://doi.org/10.1016/j.asoc.2020.106152

Wang, G., Ma, J., \& Yang, S. (2014). An improved boosting based on feature selection for corporate bankruptcy prediction. Expert Systems with Applications, 41(5), 2353-2361.

https://doi.org/10.1016/j.eswa.2013.09.033

West, R. C. (1985). A factor-analytic approach to bank condition. Journal of Banking \& Finance, 9(2), 253-266. https://doi.org/10.1016/0378-4266(85)90021-4

Xia, Y. F., Liu, C. Z., Li, Y. Y., \& Liu, N. N. (2017). A boosted decision tree approach using Bayesian hyper-parameter optimization for credit scoring. Expert Systems with Applications, 78, 225-241. https://doi.org/10.1016/j.eswa.2017.02.017

Zhou, L. G. (2013). Predicting the removal of special treatment or delisting risk warning for listed company in China with Adaboost. Procedia Computer Science, 17, 633-640. https://doi.org/10.1016/j.procs.2013.05.082

Zhou, L. G., Lu, D., \& Fujita, H. (2015). The performance of corporate financial distress prediction models with features selection guided by domain knowledge and data mining approaches. Knowledge-Based Systems, 85, 52-61. https://doi.org/10.1016/j.knosys.2015.04.017

Zhou, L. G., Tam, K. P., \& Fujita, H. (2016). Predicting the listing status of Chinese listed companies with multi-class classification models. Information Sciences, 328, 222-236. https://doi.org/10.1016/j.ins.2015.08.036

Zieba, M., Tomczak, S. K., \& Tomczak, J. M. (2016). Ensemble boosted trees with synthetic features generation in application to bankruptcy prediction. Expert Systems with Applications, 58, 93-101. https://doi.org/10.1016/j.eswa.2016.04.001 


\section{APPENDIX A}

The final specific parameters of each classifier:

DT: criterion: gini_index; maximal depth:10; confidence:0.1; minimal gain:0.01; minimal leaf size:2;

LR: solver: AUTO;

NBM: laplace correction; estimation mode: greedy; minimum bandwidth: 0.1 ; number of kernels:10;

SVM: svm type: C-SVC; kernel type: rbf; epsilon:0.001;

NN: multi-layer feed-forward artificial neural network that is trained with stochastic gradient descent using back-propagation; activation: ExpRectifier; hidden layer sizes:50,50; epochs:10; GLM: family: AUTO; solver: AUTO;

RF: number of trees:100; criterion: gini_index; maximal depth:10; voting strategy: confidence vote;

ADA: iterations:10; criterion: information_gain; maximal depth:3; confidence:0.1; minimal gain:0.01; minimal leaf size:2;

XG: number of trees:100; maximal depth:2; min rows:10; min split improvement:0; number if bins:20; learning rate:0.1; sample rate:0.47.

\section{APPENDIX B}

The original data of LOOCV (All companies)

\begin{tabular}{|c|c|c|c|c|c|c|c|c|c|}
\hline & $t-3$ & & & $\mathrm{t}-4$ & & & $t-5$ & & \\
\hline \multirow{16}{*}{$\begin{array}{l}\text { leave-one-out } \\
\text { cross validation }\end{array}$} & \multirow[t]{4}{*}{ DT } & Accuracy & 0.756 & \multirow[t]{4}{*}{ DT } & Accuracy & 0.672 & \multirow[t]{4}{*}{ DT } & Accuracy & 0.585 \\
\hline & & AUC & 0.397 & & AUC & 0.393 & & AUC & 0.383 \\
\hline & & Recall & 0.747 & & Recall & 0.666 & & Recall & 0.575 \\
\hline & & $\mathrm{F} 1$ & 0.754 & & $\mathrm{~F} 1$ & 0.667 & & $\mathrm{~F} 1$ & 0.581 \\
\hline & \multirow[t]{4}{*}{ LR } & Accuracy & 0.766 & \multirow[t]{4}{*}{ LR } & Accuracy & 0.625 & \multirow[t]{4}{*}{ LR } & Accuracy & 0.656 \\
\hline & & AUC & 0.498 & & AUC & 0.493 & & AUC & 0.500 \\
\hline & & Recall & 0.741 & & Recall & 0.612 & & Recall & 0.650 \\
\hline & & $\mathrm{F} 1$ & 0.760 & & $\mathrm{~F} 1$ & 0.617 & & $\mathrm{~F} 1$ & 0.653 \\
\hline & \multirow[t]{4}{*}{ NBM } & Accuracy & 0.742 & \multirow[t]{4}{*}{ NBM } & Accuracy & 0.641 & \multirow[t]{4}{*}{ NBM } & Accuracy & 0.623 \\
\hline & & AUC & 0.404 & & AUC & 0.426 & & AUC & 0.446 \\
\hline & & Recall & 0.687 & & Recall & 0.616 & & Recall & 0.553 \\
\hline & & F1 & 0.721 & & F1 & 0.616 & & F1 & 0.593 \\
\hline & \multirow[t]{4}{*}{ SVM } & Accuracy & 0.573 & \multirow[t]{4}{*}{ SVM } & Accuracy & 0.555 & \multirow[t]{4}{*}{ SVM } & Accuracy & 0.577 \\
\hline & & AUC & 0.500 & & AUC & 0.500 & & AUC & 0.500 \\
\hline & & Recall & 0.254 & & Recall & 0.234 & & Recall & 0.321 \\
\hline & & $\mathrm{F} 1$ & 0.373 & & $\mathrm{~F} 1$ & 0.342 & & $\mathrm{~F} 1$ & 0.432 \\
\hline
\end{tabular}


Continue of Appendix B

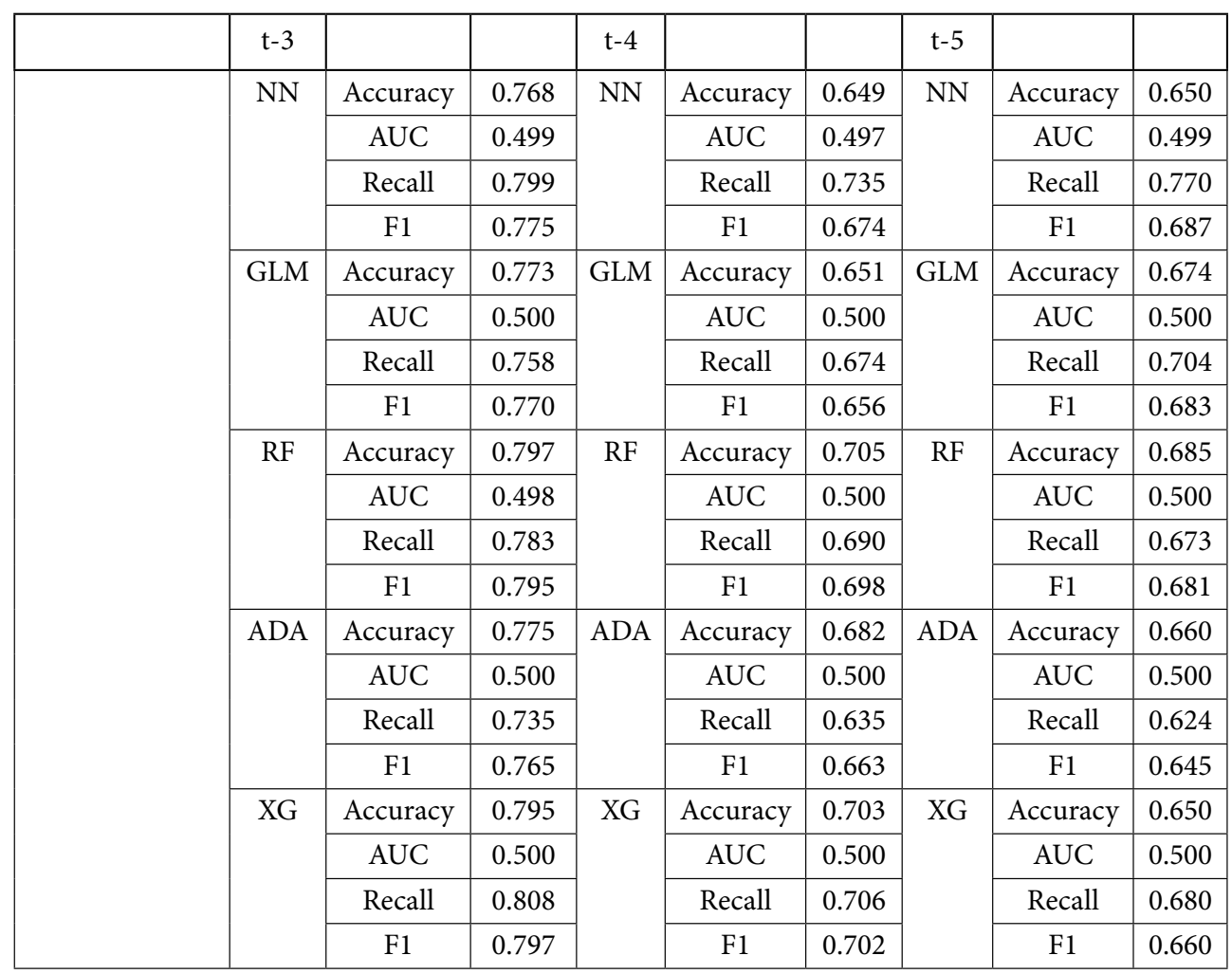

The original data of bootstrapping (All companies)

\begin{tabular}{|c|c|c|c|c|c|c|c|c|c|}
\hline & $t-3$ & & & $\mathrm{t}-4$ & & & $t-5$ & & \\
\hline \multirow[t]{16}{*}{ bootstrapping } & \multirow[t]{4}{*}{ DT } & Accuracy & 0.734 & \multirow[t]{4}{*}{ DT } & Accuracy & 0.630 & \multirow[t]{4}{*}{ DT } & Accuracy & 0.595 \\
\hline & & AUC & 0.714 & & AUC & 0.602 & & AUC & 0.569 \\
\hline & & Recall & 0.718 & & Recall & 0.610 & & Recall & 0.582 \\
\hline & & F1 & 0.730 & & $\mathrm{~F} 1$ & 0.618 & & F1 & 0.589 \\
\hline & \multirow[t]{4}{*}{ LR } & Accuracy & 0.749 & \multirow[t]{4}{*}{ LR } & Accuracy & 0.620 & \multirow[t]{4}{*}{ LR } & Accuracy & 0.638 \\
\hline & & AUC & 0.793 & & AUC & 0.645 & & AUC & 0.681 \\
\hline & & Recall & 0.723 & & Recall & 0.595 & & Recall & 0.619 \\
\hline & & $\mathrm{F} 1$ & 0.743 & & $\mathrm{~F} 1$ & 0.605 & & $\mathrm{~F} 1$ & 0.629 \\
\hline & \multirow[t]{4}{*}{ NBM } & Accuracy & 0.736 & \multirow[t]{4}{*}{ NBM } & Accuracy & 0.619 & \multirow[t]{4}{*}{ NBM } & Accuracy & 0.620 \\
\hline & & AUC & 0.736 & & AUC & 0.646 & & AUC & 0.611 \\
\hline & & Recall & 0.706 & & Recall & 0.551 & & Recall & 0.547 \\
\hline & & F1 & 0.720 & & F1 & 0.566 & & $\mathrm{~F} 1$ & 0.585 \\
\hline & \multirow[t]{4}{*}{ SVM } & Accuracy & 0.557 & \multirow[t]{4}{*}{ SVM } & Accuracy & 0.549 & \multirow[t]{4}{*}{ SVM } & Accuracy & 0.551 \\
\hline & & AUC & 0.574 & & AUC & 0.546 & & AUC & 0.566 \\
\hline & & Recall & 0.275 & & Recall & 0.237 & & Recall & 0.340 \\
\hline & & $\mathrm{F} 1$ & 0.366 & & $\mathrm{~F} 1$ & 0.330 & & $\mathrm{~F} 1$ & 0.413 \\
\hline
\end{tabular}


End of Appendix B

\begin{tabular}{|c|c|c|c|c|c|c|c|c|}
\hline$t-3$ & & & $\mathrm{t}-4$ & & & $t-5$ & & \\
\hline \multirow[t]{4}{*}{$\mathrm{NN}$} & Accuracy & 0.762 & \multirow[t]{4}{*}{$\mathrm{NN}$} & Accuracy & 0.634 & \multirow[t]{4}{*}{$\mathrm{NN}$} & Accuracy & 0.632 \\
\hline & AUC & 0.820 & & AUC & 0.692 & & AUC & 0.685 \\
\hline & Recall & 0.770 & & Recall & 0.709 & & Recall & 0.701 \\
\hline & F1 & 0.764 & & $\mathrm{~F} 1$ & 0.655 & & $\mathrm{~F} 1$ & 0.654 \\
\hline \multirow[t]{4}{*}{ GLM } & Accuracy & 0.769 & \multirow[t]{4}{*}{ GLM } & Accuracy & 0.626 & \multirow[t]{4}{*}{ GLM } & Accuracy & 0.663 \\
\hline & AUC & 0.823 & & AUC & 0.666 & & AUC & 0.713 \\
\hline & Recall & 0.749 & & Recall & 0.638 & & Recall & 0.674 \\
\hline & F1 & 0.765 & & $\mathrm{~F} 1$ & 0.625 & & $\mathrm{~F} 1$ & 0.665 \\
\hline \multirow[t]{4}{*}{$\mathrm{RF}$} & Accuracy & 0.791 & \multirow[t]{4}{*}{$\mathrm{RF}$} & Accuracy & 0.691 & \multirow[t]{4}{*}{$\mathrm{RF}$} & Accuracy & 0.674 \\
\hline & AUC & 0.869 & & AUC & 0.772 & & AUC & 0.730 \\
\hline & Recall & 0.774 & & Recall & 0.684 & & Recall & 0.659 \\
\hline & F1 & 0.788 & & F1 & 0.685 & & F1 & 0.669 \\
\hline \multirow[t]{4}{*}{$\mathrm{ADA}$} & Accuracy & 0.742 & \multirow[t]{4}{*}{$\mathrm{ADA}$} & Accuracy & 0.641 & \multirow[t]{4}{*}{$\mathrm{ADA}$} & Accuracy & 0.638 \\
\hline & AUC & 0.784 & & AUC & 0.683 & & AUC & 0.669 \\
\hline & Recall & 0.717 & & Recall & 0.631 & & Recall & 0.605 \\
\hline & $\mathrm{F} 1$ & 0.736 & & $\mathrm{~F} 1$ & 0.628 & & $\mathrm{~F} 1$ & 0.618 \\
\hline \multirow[t]{4}{*}{$\mathrm{XG}$} & Accuracy & 0.787 & \multirow[t]{4}{*}{$\mathrm{XG}$} & Accuracy & 0.678 & \multirow[t]{4}{*}{$\mathrm{XG}$} & Accuracy & 0.639 \\
\hline & AUC & 0.859 & & AUC & 0.746 & & AUC & 0.693 \\
\hline & Recall & 0.779 & & Recall & 0.693 & & Recall & 0.646 \\
\hline & F1 & 0.786 & & F1 & 0.686 & & F1 & 0.644 \\
\hline
\end{tabular}

APPENDIX C

The original data of bootstrapping (Positive companies)

\begin{tabular}{|c|c|c|c|c|c|c|c|c|c|}
\hline & $t-3$ & & & $\mathrm{t}-4$ & & & $t-5$ & & \\
\hline \multirow[t]{12}{*}{ bootstrapping } & \multirow[t]{4}{*}{$\mathrm{NN}$} & Accuracy & 0.745 & \multirow[t]{4}{*}{ NN } & Accuracy & 0.661 & \multirow[t]{4}{*}{$\mathrm{NN}$} & Accuracy & 0.641 \\
\hline & & AUC & 0.802 & & AUC & 0.716 & & AUC & 0.697 \\
\hline & & Recall & 0.730 & & Recall & 0.689 & & Recall & 0.689 \\
\hline & & $\mathrm{F} 1$ & 0.738 & & F1 & 0.669 & & $\mathrm{~F} 1$ & 0.655 \\
\hline & \multirow[t]{4}{*}{ GLM } & Accuracy & 0.764 & \multirow[t]{4}{*}{ GLM } & Accuracy & 0.659 & \multirow[t]{4}{*}{ GLM } & Accuracy & 0.669 \\
\hline & & AUC & 0.827 & & AUC & 0.715 & & AUC & 0.734 \\
\hline & & Recall & 0.725 & & Recall & 0.680 & & Recall & 0.677 \\
\hline & & F1 & 0.752 & & F1 & 0.662 & & F1 & 0.666 \\
\hline & \multirow[t]{4}{*}{$\mathrm{RF}$} & Accuracy & 0.790 & \multirow[t]{4}{*}{$\mathrm{RF}$} & Accuracy & 0.694 & \multirow[t]{4}{*}{$\mathrm{RF}$} & Accuracy & 0.686 \\
\hline & & AUC & 0.875 & & AUC & 0.759 & & AUC & 0.726 \\
\hline & & Recall & 0.746 & & Recall & 0.691 & & Recall & 0.681 \\
\hline & & F1 & 0.779 & & F1 & 0.691 & & $\mathrm{~F} 1$ & 0.682 \\
\hline
\end{tabular}


End of Appendix $C$

\begin{tabular}{|l|c|c|c|c|c|c|c|c|c|}
\hline & $\mathrm{t}-3$ & & & $\mathrm{t}-4$ & & & $\mathrm{t}-5$ & & \\
\hline & ADA & Accuracy & 0.749 & ADA & Accuracy & 0.672 & ADA & Accuracy & 0.625 \\
\hline & & AUC & 0.824 & & AUC & 0.731 & & AUC & 0.676 \\
\hline & & Recall & 0.761 & & Recall & 0.656 & & Recall & 0.592 \\
\hline & & F1 & 0.758 & & F1 & 0.660 & & F1 & 0.606 \\
\hline & XG & Accuracy & 0.784 & XG & Accuracy & 0.681 & XG & Accuracy & 0.641 \\
\hline & & AUC & 0.843 & & AUC & 0.759 & & AUC & 0.702 \\
\hline & & Recall & 0.756 & & Recall & 0.689 & & Recall & 0.630 \\
\hline & & F1 & 0.767 & & F1 & 0.690 & & F1 & 0.632 \\
\hline
\end{tabular}

The original data of bootstrapping (Negative companies)

\begin{tabular}{|c|c|c|c|c|c|c|c|c|c|}
\hline & $\mathrm{t}-3$ & & & $\mathrm{t}-4$ & & & $t-5$ & & \\
\hline \multirow[t]{20}{*}{ bootstrapping } & \multirow[t]{4}{*}{ NN } & Accuracy & 0.544 & \multirow[t]{4}{*}{$\mathrm{NN}$} & Accuracy & 0.702 & \multirow[t]{4}{*}{ NN } & Accuracy & 0.530 \\
\hline & & AUC & 0.569 & & AUC & 0.734 & & AUC & 0.527 \\
\hline & & Recall & 0.573 & & Recall & 0.656 & & Recall & 0.554 \\
\hline & & $\mathrm{F} 1$ & 0.526 & & F1 & 0.658 & & F1 & 0.513 \\
\hline & \multirow[t]{4}{*}{ GLM } & Accuracy & 0.558 & \multirow[t]{4}{*}{ GLM } & Accuracy & 0.714 & \multirow[t]{4}{*}{ GLM } & Accuracy & 0.540 \\
\hline & & AUC & 0.582 & & AUC & 0.776 & & AUC & 0.538 \\
\hline & & Recall & 0.447 & & Recall & 0.555 & & Recall & 0.416 \\
\hline & & $\mathrm{F} 1$ & 0.466 & & $\mathrm{~F} 1$ & 0.622 & & $\mathrm{~F} 1$ & 0.440 \\
\hline & \multirow[t]{4}{*}{$\mathrm{RF}$} & Accuracy & 0.551 & \multirow[t]{4}{*}{$\mathrm{RF}$} & Accuracy & 0.816 & \multirow[t]{4}{*}{$\mathrm{RF}$} & Accuracy & 0.549 \\
\hline & & AUC & 0.576 & & AUC & 0.857 & & AUC & 0.581 \\
\hline & & Recall & 0.453 & & Recall & 0.766 & & Recall & 0.465 \\
\hline & & $\mathrm{F} 1$ & 0.471 & & $\mathrm{~F} 1$ & 0.784 & & F1 & 0.477 \\
\hline & \multirow[t]{4}{*}{$\mathrm{ADA}$} & Accuracy & 0.521 & \multirow[t]{4}{*}{$\mathrm{ADA}$} & Accuracy & 0.726 & \multirow[t]{4}{*}{$\mathrm{ADA}$} & Accuracy & 0.542 \\
\hline & & AUC & 0.538 & & AUC & 0.783 & & AUC & 0.555 \\
\hline & & Recall & 0.419 & & Recall & 0.632 & & Recall & 0.405 \\
\hline & & $\mathrm{F} 1$ & 0.423 & & F1 & 0.660 & & F1 & 0.425 \\
\hline & \multirow[t]{4}{*}{$\mathrm{XG}$} & Accuracy & 0.556 & \multirow[t]{4}{*}{ XG } & Accuracy & 0.791 & \multirow[t]{4}{*}{ XG } & Accuracy & 0.561 \\
\hline & & AUC & 0.575 & & AUC & 0.845 & & AUC & 0.587 \\
\hline & & Recall & 0.506 & & Recall & 0.760 & & Recall & 0.508 \\
\hline & & $\mathrm{F} 1$ & 0.504 & & F1 & 0.763 & & F1 & 0.506 \\
\hline
\end{tabular}




\section{APPENDIX D}

\begin{tabular}{|c|c|c|c|}
\hline \multicolumn{4}{|c|}{ Feature Ranking } \\
\hline \multicolumn{4}{|c|}{$t-3$} \\
\hline all & Number & positive & Number \\
\hline $\mathrm{NP}(\mathrm{t})-\mathrm{NP}(\mathrm{t}-1) / \mathrm{NP}(\mathrm{t}-1)$ & 9 & $\mathrm{NP}(\mathrm{t})-\mathrm{NP}(\mathrm{t}-1) / \mathrm{NP}(\mathrm{t}-1)$ & 11 \\
\hline $\mathrm{TA}(\mathrm{t})-\mathrm{TA}(\mathrm{t}-1) / \mathrm{TA}(\mathrm{t}-1)$ & 7 & NDS & 6 \\
\hline SR/AFA & 6 & $\operatorname{MBI}(\mathrm{t})-\mathrm{MBI}(\mathrm{t}$ 1)/MBI$(\mathrm{t}-1)$ & 5 \\
\hline NBD & 5 & NRE & 4 \\
\hline $\mathrm{NOCF} / \mathrm{CL}$ & 5 & $\mathrm{TA}(\mathrm{t})-\mathrm{TA}(\mathrm{t}-1) / \mathrm{TA}(\mathrm{t}-1)$ & 3 \\
\hline $\mathrm{MBC} / \mathrm{AI}$ & 5 & NP/ATA & 3 \\
\hline CS/APA & 5 & NP/ACA & 3 \\
\hline NRE & 5 & NP/ASE & 2 \\
\hline EBIT/TL & 4 & $(\mathrm{SR}-\mathrm{SC}) / \mathrm{SR}$ & 2 \\
\hline NDS & 4 & MBI/ABAR & 2 \\
\hline \multicolumn{4}{|c|}{$\mathrm{t}-4$} \\
\hline all & Number & positive & Number \\
\hline$(\mathrm{CA}-\mathrm{I}) / \mathrm{CL}$ & 8 & $(\mathrm{CA}-\mathrm{I}) / \mathrm{CL}$ & 9 \\
\hline SR/AFA & 7 & $\mathrm{MBC} / \mathrm{AI}$ & 6 \\
\hline $\mathrm{NOCF} / \mathrm{CL}$ & 6 & NDS & 6 \\
\hline NP/ACA & 5 & SR/ACA & 5 \\
\hline $\mathrm{TA}(\mathrm{t})-\mathrm{TA}(\mathrm{t}-1) / \mathrm{TA}(\mathrm{t}-1)$ & 5 & $\mathrm{TA}(\mathrm{t})-\mathrm{TA}(\mathrm{t}-1) / \mathrm{TA}(\mathrm{t}-1)$ & 6 \\
\hline NDS & 5 & $\mathrm{NOCF} / \mathrm{CL}$ & 4 \\
\hline MBI/ABAR & 4 & TL/TSE & 4 \\
\hline$(\mathrm{SR}-\mathrm{SC}) / \mathrm{SR}$ & 4 & SR/AFA & 4 \\
\hline NBD & 4 & MBI/ATA & 4 \\
\hline NRE & 4 & $(\mathrm{SR}-\mathrm{SC}) / \mathrm{SR}$ & 4 \\
\hline \multicolumn{4}{|c|}{$t-5$} \\
\hline all & Number & positive & Number \\
\hline NBD & 5 & SR/AFA & 8 \\
\hline NRE & 5 & $\mathrm{NP}(\mathrm{t})-\mathrm{NP}(\mathrm{t}-1) / \mathrm{NP}(\mathrm{t}-1)$ & 7 \\
\hline TL/TA & 5 & NDS & 6 \\
\hline NP/ATA & 4 & NP/ACA & 5 \\
\hline$(\mathrm{SR}-\mathrm{SC}) / \mathrm{SR}$ & 4 & NBD & 4 \\
\hline $\mathrm{TA}(\mathrm{t})-\mathrm{TA}(\mathrm{t}-1) / \mathrm{TA}(\mathrm{t}-1)$ & 4 & TL/TA & 4 \\
\hline $\mathrm{NP}(\mathrm{t})-\mathrm{NP}(\mathrm{t}-1) / \mathrm{NP}(\mathrm{t}-1)$ & 4 & MBC/AI & 4 \\
\hline TL/TSE & 4 & NP/ASE & 4 \\
\hline SR/AFA & 4 & $\mathrm{TA}(\mathrm{t})-\mathrm{TA}(\mathrm{t}-1) / \mathrm{TA}(\mathrm{t}-1)$ & 4 \\
\hline EBIT/ATA & 4 & $\operatorname{MBI}(\mathrm{t})-\mathrm{MBI}(\mathrm{t}$ 1)/MBI(t-1) & 4 \\
\hline
\end{tabular}


Continue of Appendix D

\begin{tabular}{|c|c|c|c|}
\hline \multicolumn{4}{|c|}{ Feature Comparison } \\
\hline \multicolumn{4}{|c|}{$t-3$} \\
\hline all & & positive & \\
\hline Development & 19 & Development & 19 \\
\hline Management & 21 & Management & 8 \\
\hline Profitability & 9 & Profitability & 11 \\
\hline Solvency & 15 & Solvency & 7 \\
\hline Non-financial & 14 & Non-financial & 11 \\
\hline \multicolumn{4}{|c|}{$\mathrm{t}-4$} \\
\hline all & & positive & \\
\hline Development & 11 & Development & 10 \\
\hline Management & 20 & Management & 20 \\
\hline Profitability & 18 & Profitability & 10 \\
\hline Solvency & 20 & Solvency & 23 \\
\hline Non-financial & 13 & Non-financial & 9 \\
\hline \multicolumn{4}{|c|}{$t-5$} \\
\hline all & & positive & \\
\hline Development & 12 & Development & 15 \\
\hline Management & 16 & Management & 21 \\
\hline Profitability & 17 & Profitability & 16 \\
\hline Solvency & 19 & Solvency & 12 \\
\hline Non-financial & 13 & Non-financial & 13 \\
\hline
\end{tabular}

Results of ten feature selection experiments

\begin{tabular}{|c|c|c|c|c|c|}
\hline \multicolumn{7}{|c|}{ all companies(t-3) } \\
\hline No. & 1 & 2 & 3 & 4 & 5 \\
\hline & F012201B & F010101A & F012201B & F010801B & F011701A \\
\hline & F041702B & F010801B & F040804B & F040502B & F040202B \\
\hline & F080602A & F041204B & F041204B & F041404B & F040804B \\
\hline & F081002B & F051101B & F050302B & F051501B & F050202B \\
\hline & Y0701b & F080602A & F080602A & F081002B & F081002B \\
\hline & & F081002B & F081002B & Y0701b & Bddihldn \\
\hline & & F081602C & Y0701b & Y1601a & Y1601a \\
\hline number & 5 & 7 & Bddihldn & & 7 \\
\hline No. & 6 & 7 & 8 & 7 & 10 \\
\hline & F010201A & F010801B & F010801B & F010801B & F010101A \\
\hline & F012201B & F040502B & F041204B & F011201A & F040502B \\
\hline
\end{tabular}


Continue of Appendix D

\begin{tabular}{|c|c|c|c|c|c|}
\hline & F040502B & F040804B & F053301B & F011701A & F041204B \\
\hline & F040804B & F041204B & F080602A & F012201B & F041702B \\
\hline & F051501B & F050202B & F081002B & F040502B & F051101B \\
\hline & F080602A & F080602A & Bddihldn & F040804B & F053301B \\
\hline & F081002B & F081002B & Y1601a & F041204B & F081002B \\
\hline & Bddihldn & F081602C & & F080602A & Y0701b \\
\hline & & Bddihldn & & F081602C & Y1601a \\
\hline & & & & Y0701b & \\
\hline number & 8 & 9 & 7 & 10 & 10 \\
\hline No. & Accuracy & AUC & Recall & $\mathrm{F} 1$ & \\
\hline 1 & 0.863333333 & 0.934463659 & 0.867744361 & 0.862937157 & \\
\hline 2 & 0.803076923 & 0.860149123 & 0.848220551 & 0.81117479 & \\
\hline 3 & 0.838205128 & 0.920092732 & 0.857794486 & 0.83996903 & \\
\hline 4 & 0.838333333 & 0.924757519 & 0.849273183 & 0.839590326 & \\
\hline 5 & 0.848589744 & 0.917741855 & 0.828646617 & 0.84374635 & \\
\hline 6 & 0.812948718 & 0.873200501 & 0.849273183 & 0.819520259 & \\
\hline 7 & 0.858589744 & 0.934774436 & 0.877794486 & 0.860546644 & \\
\hline 8 & 0.838333333 & 0.873815789 & 0.888320802 & 0.846411463 & \\
\hline 9 & 0.857820513 & 0.927632206 & 0.846215539 & 0.854404591 & \\
\hline 10 & 0.868717949 & 0.931780702 & 0.899899749 & 0.872116501 & \\
\hline average & 0.842794872 & 0.909840852 & 0.861318296 & 0.845041711 & \\
\hline \multicolumn{6}{|c|}{ all companies $(\mathrm{t}-4)$} \\
\hline \multirow[t]{15}{*}{ No. } & 1 & 2 & 3 & 4 & 5 \\
\hline & F010201A & F010201A & F010201A & F010201A & F010101A \\
\hline & F010801B & F010801B & F010801B & F040502B & F010201A \\
\hline & F011201A & F041404B & F040202B & F041404B & F010801B \\
\hline & F050302B & F050202B & F040502B & F050302B & F011201A \\
\hline & F081002B & F050302B & F041404B & F051101B & F040202B \\
\hline & Y0701b & F051501B & F050202B & F080602A & F040804B \\
\hline & & F080602A & F050502B & F081602C & F041404B \\
\hline & & & F053301B & Y0701b & F050202B \\
\hline & & & F051501B & & F051101B \\
\hline & & & F080602A & & F081002B \\
\hline & & & Y1601a & & F081602C \\
\hline & & & & & Y0701b \\
\hline & & & & & Bddihldn \\
\hline & & & & & Y1601a \\
\hline number & 6 & 7 & 11 & 8 & 14 \\
\hline
\end{tabular}


Continue of Appendix D

\begin{tabular}{|c|c|c|c|c|c|}
\hline No. & 6 & 7 & 8 & 9 & 10 \\
\hline & F010101A & F041204B & F010101A & F010201A & F040202B \\
\hline & F010201A & F053301B & F010201A & F041404B & F040502B \\
\hline & F010801B & F051501B & F010801B & F041702B & F040804B \\
\hline & F011201A & F081002B & F040202B & F050302B & F050302B \\
\hline & F041204B & F081602C & F041204B & F053301B & F080602A \\
\hline & F041404B & Bddihldn & F041404B & Y0701b & Bddihldn \\
\hline & F053301B & Y1601a & F080602A & Bddihldn & Y1601a \\
\hline & & & & Y1601a & \\
\hline number & 7 & 7 & 7 & 8 & 7 \\
\hline No. & Accuracy & AUC & Recall & $\mathrm{F} 1$ & \\
\hline 1 & 0.76025641 & 0.846789474 & 0.786315789 & 0.762203642 & \\
\hline 2 & 0.739102564 & 0.822605263 & 0.723684211 & 0.736595334 & \\
\hline 3 & 0.795769231 & 0.850815789 & 0.835789474 & 0.801969438 & \\
\hline 4 & 0.75974359 & 0.828263158 & 0.806842105 & 0.775455109 & \\
\hline 5 & 0.73474359 & 0.841921053 & 0.805789474 & 0.752186161 & \\
\hline 6 & 0.791025641 & 0.888394737 & 0.795263158 & 0.788285457 & \\
\hline 7 & 0.750128205 & 0.805368421 & 0.756315789 & 0.751118204 & \\
\hline 8 & 0.786153846 & 0.821815789 & 0.847894737 & 0.798959038 & \\
\hline 9 & 0.785897436 & 0.830907895 & 0.826315789 & 0.792891986 & \\
\hline 10 & 0.709102564 & 0.777447368 & 0.767368421 & 0.721737528 & \\
\hline average & 0.761192308 & 0.831432895 & 0.795157895 & 0.76814019 & \\
\hline \multicolumn{6}{|c|}{ all companies(t-5) } \\
\hline \multirow[t]{13}{*}{ No. } & 1 & 2 & 3 & 4 & 5 \\
\hline & F040202B & F011701A & F010101A & F010801B & F011201A \\
\hline & F040502B & F041404B & F010201A & F011201A & F041204B \\
\hline & F040804B & F051101B & F010801B & F011701A & F041404B \\
\hline & F050202B & F080602A & F011201A & F041404B & F050202B \\
\hline & F053301B & F081602C & F040502B & F041702B & F050502B \\
\hline & F080602A & Y0701b & F041404B & F050302B & F081602C \\
\hline & F081002B & Bddihldn & F041702B & F081602C & Bddihldn \\
\hline & Bddihldn & & F051101B & & \\
\hline & & & F080602A & & \\
\hline & & & F081002B & & \\
\hline & & & Y0701b & & \\
\hline & & & Y1601a & & \\
\hline number & 8 & 7 & 12 & 7 & 7 \\
\hline
\end{tabular}


Continue of Appendix D

\begin{tabular}{|c|c|c|c|c|c|c|c|c|}
\hline No. & 6 & \multicolumn{2}{|l|}{7} & \multicolumn{2}{|c|}{8} & \multicolumn{2}{|r|}{9} & 10 \\
\hline & F010801B & \multicolumn{2}{|c|}{ F011201A } & \multicolumn{2}{|c|}{ F010101A } & \multicolumn{2}{|c|}{ F041204B } & F010101A \\
\hline & F011201A & \multicolumn{2}{|c|}{ F012201B } & \multicolumn{2}{|c|}{ F010801B } & \multicolumn{2}{|c|}{ F041702B } & F011701A \\
\hline & F041204B & \multicolumn{2}{|c|}{ F053301B } & \multicolumn{2}{|c|}{ F011701A } & \multicolumn{2}{|c|}{ F050502B } & F012201B \\
\hline & F050202B & \multicolumn{2}{|c|}{ F051501B } & \multicolumn{2}{|c|}{ F041702B } & \multicolumn{2}{|c|}{ F080602A } & F040502B \\
\hline & F053301B & \multicolumn{2}{|c|}{ F081002B } & \multicolumn{2}{|c|}{ F051101B } & \multicolumn{2}{|c|}{ Y0701b } & F050202B \\
\hline & Y0701b & \multicolumn{2}{|c|}{ Bddihldn } & \multicolumn{2}{|c|}{ F053301B } & \multicolumn{2}{|r|}{ Y1601a } & F051101B \\
\hline & Bddihldn & & & \multicolumn{2}{|c|}{ F051501B } & & & F081002B \\
\hline & Y1601a & & & \multicolumn{2}{|c|}{ F081602C } & & & Y0701b \\
\hline number & 8 & 6 & & & & & 6 & 8 \\
\hline No. & Accuracy & AUC & & & & & F1 & \\
\hline 1 & 0.706882591 & 0.736592 & & 0.700 & 26316 & & 01051794 & \\
\hline 2 & 0.736842105 & 0.781551 & & 0.701 & 52632 & & 27324166 & \\
\hline 3 & 0.732118758 & 0.789473 & & 0.774 & 10526 & & 45979242 & \\
\hline 4 & 0.736842105 & 0.831662 & & 0.786 & 42105 & & 40238928 & \\
\hline 5 & 0.711740891 & 0.806897 & & 0.692 & 05263 & & 01651652 & \\
\hline 6 & 0.7682861 & 0.792977 & & 0.825 & 63158 & & 79739772 & \\
\hline 7 & 0.726990553 & 0.776731 & & 0.774 & 10526 & & 38802449 & \\
\hline 8 & 0.70634278 & 0.773504 & & 0.742 & 31579 & & 14633036 & \\
\hline 9 & 0.747233468 & 0.842354 & & 0.785 & 89474 & & 54806202 & \\
\hline 10 & 0.69122807 & 0.798213 & & 0.742 & 05263 & & 08142256 & \\
\hline average & 0.726450742 & 0.792995 & & 0.752 & 73684 & & 3123695 & \\
\hline & & positive & mpa & $\operatorname{lies}(t-3)$ & & & & \\
\hline No. & 1 & 2 & & 3 & 4 & & 5 & \\
\hline & F040502B & F040804B & F01 & $201 \mathrm{~A}$ & F0117 & & F040202B & \\
\hline & F050302B & F050302B & & 0502B & F081C & & F050202B & \\
\hline & F081002B & F053301B & & $1204 B$ & F0816 & & F081002B & \\
\hline & Y0701b & F080602A & & 0502B & Y07 & & Y1601a & \\
\hline & & F081002B & & $3301 \mathrm{~B}$ & & & & \\
\hline & & F081602C & & $0602 \mathrm{~A}$ & & & & \\
\hline & & Y1601a & & $1002 B$ & & & & \\
\hline & & & & $1602 \mathrm{C}$ & & & & \\
\hline & & & & $601 \mathrm{a}$ & & & & \\
\hline number & 5 & 7 & & 9 & 4 & & 4 & \\
\hline No. & 6 & 7 & & 8 & 9 & & 10 & 11 \\
\hline & F010801B & F011701A & F01 & $201 \mathrm{~A}$ & F0502 & & F081002B & F010101A \\
\hline & F011201A & F050202B & & 0202B & F081C & $2 \mathrm{~B}$ & F081602C & F040804B \\
\hline & F050302B & F081002B & & 0502B & Y16 & & Y0701b & F041204B \\
\hline & F081002B & F081602C & & $1002 B$ & & & & F051101B \\
\hline & Y0701b & & & $601 \mathrm{a}$ & & & & F080602A \\
\hline & Bddihldn & & & & & & & F081002B \\
\hline & Y1601a & & & & & & & \\
\hline number & 7 & 4 & & 5 & 3 & & 3 & 6 \\
\hline
\end{tabular}


Continue of Appendix D

\begin{tabular}{|c|c|c|c|c|c|c|}
\hline No. & Accuracy & AUC & Recall & $\mathrm{F} 1$ & & \\
\hline 1 & 0.894102564 & 0.90543985 & 0.838270677 & 0.888165018 & & \\
\hline 2 & 0.863974359 & 0.904028195 & 0.857794486 & 0.863923157 & & \\
\hline 3 & 0.843589744 & 0.881862155 & 0.817744361 & 0.839243662 & & \\
\hline 4 & 0.874102564 & 0.907202381 & 0.838796992 & 0.86981157 & & \\
\hline 5 & 0.873461538 & 0.903884712 & 0.857318296 & 0.871008397 & & \\
\hline 6 & 0.878589744 & 0.908058897 & 0.837794486 & 0.874813684 & & \\
\hline 7 & 0.888717949 & 0.907406015 & 0.84726817 & 0.88398678 & & \\
\hline 8 & 0.898974359 & 0.912649123 & 0.847794486 & 0.893098703 & & \\
\hline 9 & 0.873717949 & 0.870781955 & 0.848270677 & 0.871411186 & & \\
\hline 10 & 0.873974359 & 0.906308897 & 0.868370927 & 0.872996073 & & \\
\hline 11 & 0.884102564 & 0.906328321 & 0.878847118 & 0.884276365 & & \\
\hline average & 0.877027972 & 0.901268227 & 0.848933698 & 0.873884963 & & \\
\hline & & & sitive compan & iies $(\mathrm{t}-4)$ & & \\
\hline No. & 1 & 2 & & 3 & 4 & 5 \\
\hline & F010201A & F0102 & $01 \mathrm{~A}$ & $010101 \mathrm{~A}$ & F010201A & F010101A \\
\hline & F041702B & F0402 & $202 \mathrm{~B}$ & $010201 \mathrm{~A}$ & F010801B & F010201A \\
\hline & F050302B & F0405 & 502B & $010801 \mathrm{~B}$ & F011701A & F012201B \\
\hline & F053301B & F0412 & 204B & $011701 \mathrm{~A}$ & F012201B & F040502B \\
\hline & F051501B & F0414 & 104B & $040502 B$ & F040502B & F041702B \\
\hline & F080602A & F0417 & 702B & $050302 \mathrm{~B}$ & F041404B & Y1601a \\
\hline & F081002B & F0533 & $01 \mathrm{~B}$ & $080602 \mathrm{~A}$ & F041702B & \\
\hline & Y1601a & $\overline{\text { F0806 }}$ & $02 \mathrm{~A}$ & Y1601a & F050502B & \\
\hline & & Bddih & ldn & & & \\
\hline number & 8 & 9 & & 8 & 8 & 6 \\
\hline No. & 6 & 7 & & 8 & 9 & 10 \\
\hline & F010101A & F0405 & 02B & $010201 \mathrm{~A}$ & F010201A & F010201A \\
\hline & F010201A & F0414 & 104B & $041204 \mathrm{~B}$ & F010801B & F010801B \\
\hline & F011701A & F0503 & $02 \mathrm{~B}$ & $053301 \mathrm{~B}$ & F012201B & F011701A \\
\hline & F041204B & Y070 & $1 \mathrm{~b}$ & $080602 \mathrm{~A}$ & F041204B & F040502B \\
\hline & F081002B & Bddih & ldn & $081002 B$ & F041404B & F041204B \\
\hline & F081602C & & & Y1601a & F080602A & F050502B \\
\hline & & & & & Y1601a & F053301B \\
\hline & & & & & & F081602C \\
\hline & & & & & & Y1601a \\
\hline number & 6 & 5 & & 6 & 7 & 9 \\
\hline
\end{tabular}


Continue of Appendix D

\begin{tabular}{|c|c|c|c|c|c|}
\hline No. & Accuracy & AUC & Recall & F1 & \\
\hline 1 & 0.801282051 & 0.829552632 & 0.795789474 & 0.799387572 & \\
\hline 2 & 0.754871795 & 0.766184211 & 0.694736842 & 0.738705739 & \\
\hline 3 & 0.805897436 & 0.830881579 & 0.806315789 & 0.805573549 & \\
\hline 4 & 0.806282051 & 0.823539474 & 0.776315789 & 0.801787727 & \\
\hline 5 & 0.79025641 & 0.813921053 & 0.755263158 & 0.782849431 & \\
\hline 6 & 0.76 & 0.776526316 & 0.753684211 & 0.759365722 & \\
\hline 7 & 0.765128205 & 0.760736842 & 0.776315789 & 0.766965491 & \\
\hline 8 & 0.811153846 & 0.848157895 & 0.806842105 & 0.810013015 & \\
\hline 9 & 0.820897436 & 0.858631579 & 0.806842105 & 0.816559269 & \\
\hline 10 & 0.790384615 & 0.806473684 & 0.755263158 & 0.782450954 & \\
\hline average & 0.790615385 & 0.811460526 & 0.772736842 & 0.786365847 & \\
\hline \multicolumn{6}{|c|}{ positive companies(t-5) } \\
\hline \multirow[t]{11}{*}{ No. } & 1 & 2 & 3 & 4 & 5 \\
\hline & F040502B & F011201A & F010101A & F041404B & F010101A \\
\hline & F040804B & F041204B & F011201A & F050302B & F011201A \\
\hline & F041404B & F041404B & F011701A & F080602A & F040202B \\
\hline & F050302B & F050302B & F040502B & F081602C & F040804B \\
\hline & F050502B & F051101B & F041404B & Y0701b & F050502B \\
\hline & F053301B & F081002B & F081002B & Y1601a & F051101B \\
\hline & Y1601a & Bddihldn & F081602C & & F080602A \\
\hline & & & Y0701b & & F081002B \\
\hline & & & Bddihldn & & \\
\hline & & & Y1601a & & \\
\hline number & 7 & 7 & 10 & 6 & 8 \\
\hline \multirow[t]{11}{*}{ No. } & 6 & 7 & 8 & 9 & 10 \\
\hline & F010801B & F010201A & F041204B & F011701A & F010101A \\
\hline & F040502B & F011701A & F041404B & F041404B & F011201A \\
\hline & F041204B & F041702B & F050302B & F041702B & F040502B \\
\hline & F041404B & F050502B & F053301B & F080602A & F040804B \\
\hline & F051501B & F053301B & F081002B & F081002B & F041404B \\
\hline & F081002B & F081602C & Bddihldn & Y0701b & F050302B \\
\hline & F081602C & Bddihldn & Y1601a & Y1601a & F050502B \\
\hline & & Y1601a & & & F051101B \\
\hline & & & & & F080602A \\
\hline & & & & & F081002B \\
\hline number & 7 & 8 & 7 & 7 & 10 \\
\hline
\end{tabular}


End of Appendix D

\begin{tabular}{|c|c|c|c|c|c|}
\hline No. & accuracy & AUC & recall & f_measure & \\
\hline 1 & 0.799055331 & 0.802880886 & 0.794210526 & 0.796534627 & \\
\hline 2 & 0.773279352 & 0.778033241 & 0.774736842 & 0.771135155 & \\
\hline 3 & 0.741835358 & 0.763573407 & 0.755263158 & 0.742168728 & \\
\hline 4 & 0.742375169 & 0.754418283 & 0.682105263 & 0.722205422 & \\
\hline 5 & 0.727395412 & 0.735221607 & 0.702631579 & 0.718856083 & \\
\hline 6 & 0.721997301 & 0.736481994 & 0.734210526 & 0.724550225 & \\
\hline 7 & 0.726990553 & 0.743684211 & 0.704210526 & 0.716619067 & \\
\hline 8 & 0.763157895 & 0.783227147 & 0.734210526 & 0.757791434 & \\
\hline 9 & 0.768556005 & 0.785484765 & 0.764736842 & 0.769490254 & \\
\hline 10 & 0.767746289 & 0.813601108 & 0.762631579 & 0.75964588 & \\
\hline average & 0.753238866 & 0.769660665 & 0.740894737 & 0.747899687 & \\
\hline
\end{tabular}

